\title{
Using Asset Prices to Measure the Persistence of the Marginal Utility of Wealth
}

\author{
Fernando Alvarez* \\ University of Chicago, Universidad Torcuato Di Tella, and NBER
}

Urban J. Jermann

The Wharton School of the University of Pennsylvania, and NBER

January 10, 2002

\begin{abstract}
We derive a lower bound for the size of the permanent component of investors' marginal utility of wealth, or more generally, asset pricing kernels. The bound is based on return properties of long-term zero-coupon bonds, risk-free bonds, and other risky securities. We find the permanent component of the pricing kernel to be very large; its volatility is about at least as large as the volatility of the stochastic discount factor. We also show that, for many cases where the pricing kernel is a function of consumption, innovations to consumption need to have permanent effects.

[Keywords: Pricing kernel, stochastic discount factor, permanent component, unit roots]
\end{abstract}

${ }^{*}$ We thank Andy Atkeson, Lars Hansen, Pat Kehoe, Bob King, Narayana Kocherlakota, Stephen Leroy, Lee Ohanian, and the participants in workshops and conferences at UCLA, the University of Chicago, the Federal Reserve Banks of Minneapolis, Chicago, and Cleveland, and Duke, Boston, Ohio State and Georgetown Universities, NYU, Wharton, SED meeting in Stockholm, SITE and Minnesota workshop in macroeconomic theory for their comments and suggestions. We thank Robert Bliss for providing the data for U.S. zero-coupon bonds. Earlier versions of this paper circulated as "The size of the permanent component of asset pricing kernels." Alvarez thanks the NSF and the Sloan Foundation for support. Corresponding author: U. Jermann, Finance Department, The Wharton School of the University of Pennsylvania, 3620 Locust Walk, Philadelphia, PA 19104. 


\section{Introduction}

The absence of arbitrage opportunities implies the existence of a pricing kernel, that is, a stochastic process that assigns values to state-contingent payments. As is well known, asset pricing kernels can be thought of as investors' marginal utility of wealth in frictionless markets. Since the properties of such processes are important for asset pricing they have been the focus of much recent research. ${ }^{1}$ In particular, for long-lived securities the persistence properties of pricing kernels are important determinants of their prices.

The main result of this paper is to derive and estimate a lower bound for the size of the permanent component of asset pricing kernels. The bound is based on return properties of longterm zero-coupon bonds, risk-free bonds, and other risky securities. We find the permanent component of pricing kernels to be very large; its volatility is about at least as large as the volatility of the stochastic discount factor.

Our results complement the seminal work by Hansen and Jagannathan (1991). They use noarbitrage conditions to derive bounds on the volatility of pricing kernels as a function of observed asset prices. They find that, to be consistent with the high Sharpe ratios in the data, stochastic discount factors have to be very volatile. We find that, to be consistent with the low returns on long-term bonds relative to equity, the permanent component of the pricing kernel has to be very large.

Asset pricing models link pricing kernels to the underlying economic fundamentals. Thus, our analysis provides some insights into the long-term properties of these fundamentals and into the functions linking pricing kernels to the fundamentals. Along this dimension, we have two sets of results.

First, under some assumptions about the function of the marginal utility of wealth, we derive sufficient conditions on consumption so that the pricing kernel has no permanent innovations. We present several examples of utility functions for which the existence of an invariant distribution of consumption implies pricing kernels with no permanent innovations. Thus, these examples are inconsistent with our main findings. This result is useful for macroeconomics because, for some issues, the persistence properties of the processes specifying economic variables can be very important. For instance, on the issue of the welfare costs of economic uncertainty, see

\footnotetext{
${ }^{1}$ A few prominent examples of research in this line are Hansen and Jagannathan (1991), Cochrane and Hansen (1992), Luttmer (1996).
} 
Dolmas (1998) and Alvarez and Jermann (2000a); on the issue of the volatility of macroeconomic variables such as consumption, investment, and hours worked, see Hansen (1997); and on the issue of international business cycle comovements, see Baxter and Crucini (1995).

Following Nelson and Plosser (1982) a large body of literature has tested macroeconomic time-series for stationarity versus unit roots. Asset prices have also been included in multivariate analyses of persistence of GDP and consumption, see for instance, Lettau and Ludvigson (2001). We introduce new information about persistence by focusing on prices of long-term bonds. Prices of long-term bonds are particularly informative about the persistence of pricing kernels because they are the market's forecasts of the long-term changes in the pricing kernel.

Second, measuring the size of the permanent component in consumption directly and comparing it to the size of the permanent component of pricing kernels provides guidance for the specification of functions of the marginal utility of wealth. ${ }^{2}$ Specifically, we find the size of the permanent component of consumption to be lower than that of pricing kernels. This suggests the use of utility functions that magnify the permanent component.

The rest of the paper is structured as follows. Section 2 contains definitions and theoretical results. Section 3 presents empirical evidence. Section 4 relates pricing kernels and aggregate consumption. Section 5 concludes. Proofs are in Appendix A. Appendix B describes the data sources. Appendix C addresses a small sample bias.

\section{Definitions and Theoretical Results}

We start by stating some results about long-term discount bonds. Specifically, we present an inequality linking the term spread of interest rates to the excess returns on any security. This inequality holds for pricing kernels that have no permanent innovations. We then consider the case of a pricing kernel whose innovations have permanent and transitory components, and we present a lower bound for the size of the permanent component. We show how to interpret this lower bound for some classes of lognormal processes. We end this section with a result stating the conditions under which a decomposition into permanent and transitory components exist.

Let $D_{t+k}$ be a state-contingent dividend to be paid at time $t+k$ and let $V_{t}\left(D_{t+k}\right)$ be the current price of a claim to this dividend. Then, as can be seen, for instance, in Duffie (1996),

\footnotetext{
${ }^{2}$ See Daniel and Marshall (2001) on the related issue of how consumption and asset prices are correlated at different frequencies.
} 
arbitrage opportunities are ruled out in frictionless markets if and only if a strictly positive pricing kernel or state-price process, $\left\{M_{t}\right\}$, exists so that

$$
V_{t}\left(D_{t+k}\right)=\frac{E_{t}\left[M_{t+k} \cdot D_{t+k}\right]}{M_{t}} .^{3}
$$

For our results, it is important to distinguish between the pricing kernel, $M_{t+1}$, and the stochastic discount factor, $M_{t+1} / M_{t}{ }^{4}$ We use $R_{t+1}$ for the gross return on a generic portfolio held from $t$ to $t+1$; hence,(2.1) implies that

$$
1=E_{t}\left[\frac{M_{t+1}}{M_{t}} \cdot R_{t+1}\right]
$$

We define $R_{t+1, k}$ as the gross return from holding from time $t$ to time $t+1$ a claim to one unit of the numeraire to be delivered at time $t+k$,

$$
R_{t+1, k}=\frac{V_{t+1}\left(1_{t+k}\right)}{V_{t}\left(1_{t+k}\right)}
$$

The holding return on this discount bond is the ratio of the price at which the bond is sold, $V_{t+1}\left(1_{t+k}\right)$, to the price at which it was bought, $V_{t}\left(1_{t+k}\right)$. With this convention, $V_{t}\left(1_{t}\right) \equiv 1$. Thus, for $k \geq 2$ the return consists solely of capital gains; for $k=1$, the return is risk free. Finally, we define the continuously compounded term premium for a $k$-period discount bond as

$$
h_{t}(k) \equiv E_{t}\left\{\log \left[\frac{R_{t+1, k}}{R_{t+1,1}}\right]\right\},
$$

that is, the expected log excess return on the $k$-period discount bond.

We now define a condition for pricing kernels that turns out to be key for the properties of long-term bonds.

Definition 1 We say that a pricing kernel has no permanent innovations at $t$, if

$$
\lim _{k \rightarrow \infty} E_{t}\left\{\log \frac{E_{t+1}\left[M_{t+k}\right]}{E_{t}\left[M_{t+k}\right]}\right\}=0 .
$$

Under regularity conditions, this definition is equivalent to assuming that

$$
\lim _{k \rightarrow \infty} \frac{E_{t+1}\left[M_{t+k}\right]}{E_{t}\left[M_{t+k}\right]}=1
$$

in distribution. ${ }^{5}$ This can be seen by using Jensen's inequality and the law of iterative expec-

\footnotetext{
${ }^{3} \mathrm{As}$ is well known, this result does not require complete markets, but assumes that portfolio restrictions do not bind for some agents. This last condition is sufficient, but not necessary, for the existence of a pricing kernel. For instance, in Alvarez and Jermann (2000b), portfolio restrictions bind most of the time; nevertheless, a pricing kernel exists that satisfyies (2.1).

${ }^{4}$ For instance, in the Lucas representative agent model, the pricing kernel $M_{t}$ is given by $\beta^{t} U^{\prime}\left(c_{t}\right)$, where $\beta$ is the preference time discount factor and $U^{\prime}\left(c_{t}\right)$ is the marginal utility of consumption. In this case, the stochastic discount factor, $M_{t+1} / M_{t}$, is given by $\beta U^{\prime}\left(c_{t+1}\right) / U^{\prime}\left(c_{t}\right)$.

${ }^{5}$ It is sufficient that $0<\underline{x} \leq E_{t+1}\left[M_{t+k}\right] / E_{t}\left[M_{t+k}\right] \leq \bar{x}<\infty$ for all $k$.
} 
tations. Thus, condition (2.3) can only be satisfied if the ratio of expectations converges to its (constant) mean. We say that there are no permanent innovations because, as the forecasting horizons $k$ become longer, information arriving at $t+1$ will not lead to revisions of the forecasts made with current period $t$ information. Alternatively, condition (2.3) says that innovations in the forecasts of the pricing kernel have limited persistence, since their effect vanishes for large $k$. Formally, we will use the definition in condition (2.3) because it requires no further auxiliary assumptions; it also turns out to be easier to check in our examples.

A. Pricing kernels with no permanent innovations

In this section we state an important result for zero-coupon bonds if pricing kernels have no permanent innovations and we discuss some of its implications.

Proposition 2 If a pricing kernel has no permanent innovations, then

$$
h_{t}(\infty) \equiv \lim _{k \rightarrow \infty} h_{t}(k) \geq E_{t}\left[\log \left(\frac{R_{t+1}}{R_{t+1,1}}\right)\right],
$$

where $R_{t+1}$ is the holding return on any asset.

Proposition 2 states that without permanent innovations, the term spread is the highest (log) risk premium.

We present here an intuitive proof of Proposition 2 that uses the slightly stronger notion of no permanent innovations than the one defined in condition (2.3). A formal proof of Proposition 2 is in Appendix A.

The holding return to a $k$-period discount bond can be written as

$$
R_{t+1, k}=\frac{V_{t+1}\left(1_{t+k}\right)}{V_{t}\left(1_{t+k}\right)}=\frac{M_{t}}{M_{t+1}} \cdot \frac{E_{t+1}\left[M_{t+k}\right]}{E_{t}\left[M_{t+k}\right]} .
$$

Under the slightly stronger version of no permanent innovations, as defined in equation (2.4), we can write the limiting holding return as $R_{t+1, \infty}=M_{t} / M_{t+1}$. Then, for any return $R_{t+1}$, for which $E_{t}\left(\frac{M_{t+1}}{M_{t}} R_{t+1}\right)=1$, we have by Jensen's inequality that $E_{t} \log \left(\frac{M_{t+1}}{M_{t}} R_{t+1}\right) \leq \log E_{t}\left(\frac{M_{t+1}}{M_{t}} R_{t+1}\right)=$ $\log (1)=0$ and thus

$$
E_{t} \log R_{t+1} \leq E_{t} \log \frac{M_{t}}{M_{t+1}}
$$

with equality if $R_{t+1}=M_{t} / M_{t+1}$.

Proposition 2 essentially restates results presented in earlier studies in such a way as to allow for our subsequent extensions. Kazemi (1992) shows that in a Markov economy with a limiting 
stationary distribution, the return on the discount bond with the longest maturity equals the stochastic discount factor. Growth optimal returns were analyzed in Cochrane (1992) and Bansal and Lehmann (1997). Campbell, Kazemi, and Nanisetty (1999) note the relationship between the growth optimal portfolio and the return on asymptotic discount bonds.

We illustrate Proposition 2 for a kernel whose logarithm follows an infinite moving-average process with normal innovations. We show that if this process is covariance stationary, then condition (2.3) is satisfied, that is, there are no permanent innovations. Assume that

$$
M_{t}=\beta(t) \exp \left(\sum_{j=0}^{\infty} \alpha_{j} \varepsilon_{t-j}\right),
$$

with $\varepsilon_{t} \sim N\left(0, \sigma^{2}\right), \alpha_{0}=1$, and $\beta(\cdot)$ a function of time. Then

$$
E_{t} \log \frac{E_{t+1}\left[M_{t+k}\right]}{E_{t}\left[M_{t+k}\right]}=-\frac{1}{2}\left(\alpha_{k-1}\right)^{2} \sigma^{2} .
$$

If $M_{t} / \beta(t)$ is covariance stationary, so that the variance is finite and independent of time, we have that $\lim _{k \rightarrow \infty}\left(\alpha_{k-1}\right)^{2}=0$, and the condition of no permanent innovations is satisfied. It also follows directly that

$$
E\left[h_{t}(\infty)\right]=\frac{\sigma^{2}}{2}
$$

Recall that $\sigma$ is the conditional volatility of the discount factor or, equivalently, the volatility of the innovations of the pricing kernel. This last equation illustrates that if a pricing kernel has no permanent innovations, then the volatility of the innovations of the pricing kernel is tightly linked to the term premium. Hansen and Jagannathan (1991) and Cochrane and Hansen (1992) show that the conditional volatility of the discount factor is quite large, so a pricing kernel without permanent innovations will produce a counterfactually large term premium.

\section{B. Pricing kernels with permanent and transitory components}

So far, we have focused on kernels that have either permanent innovations or not. We now assume that kernels have both a permanent and a transitory component, with the objective to quantify the size of the permanent component. In the spirit of Beveridge and Nelson (1981) and Cochrane (1988), we assume that the permanent component is a martingale. As the main theoretical result of the paper, we bound the volatility of the permanent component of the discount factor relative to the total volatility.

Assume that the kernel satisfies $M_{t}=M_{t}^{T} M_{t}^{P}$ where $M_{t}^{T}$ is the transitory component and $M_{t}^{P}$ is the permanent component. We assume that for $M_{t}^{T}(2.3)$ holds, and that $M_{t}^{P}$ is a martingale, 
so that $E_{t} M_{t+1}^{P}=M_{t}^{P}$. Let the scaled conditional covariance $v_{t, t+k}$ be defined as

$$
v_{t, t+k} \equiv \frac{\operatorname{cov}_{t}\left[M_{t+k}^{T}, M_{t+k}^{P}\right]}{E_{t}\left[M_{t+k}^{T}\right] E_{t}\left[M_{t+k}^{P}\right]} .
$$

For the next proposition, we assume that $v_{t, t+k}$ satisfies the following regularity condition

$$
\lim _{k \rightarrow \infty} E_{t}\left[\log \frac{\left(1+v_{t+1, t+k}\right)}{\left(1+v_{t, t+k}\right)}\right]=0 \text { almost surely. }
$$

Using $J_{t}\left(x_{t+1}\right) \equiv \log E_{t} x_{t+1}-E_{t} \log x_{t+1}$, and $J\left(x_{t+1}\right) \equiv \log E x_{t+1}-E \log x_{t+1}$ as measures of conditional and unconditional volatility of $x_{t+1}$, we show the following result.

Proposition 3 Assume that the pricing kernel has temporary and permanent components as stated above, and that regularity condition (2.6) holds. Then (i) the conditional volatility of the permanent component satisfies

$$
J_{t}\left(\frac{M_{t+1}^{P}}{M_{t}^{P}}\right) \geq E_{t} \log \frac{R_{t+1}}{R_{t+1,1}}-h_{t}(\infty),
$$

for any return $R_{t+1}$. Furthermore, if $-E\left[h_{t}(\infty)\right] \leq J\left(1 / R_{t+1,1}\right)$, (ii) the unconditional volatility of the permanent component satisfies,

$$
\frac{J\left(\frac{M_{t+1}^{P}}{M_{t}^{P}}\right)}{J\left(\frac{M_{t+1}}{M_{t}}\right)} \geq \frac{E\left[\log \frac{R_{t+1}}{R_{t+1,1}}\right]-E\left[h_{t}(\infty)\right]}{E\left[\log \frac{R_{t+1}}{R_{t+1,1}}\right]+J\left(1 / R_{t+1,1}\right)},
$$

for any return $R_{t+1}$, and otherwise $J\left(\frac{M_{t+1}^{P}}{M_{t}^{P}}\right) / J\left(\frac{M_{t+1}}{M_{t}}\right)>1$.

Inequality (2.7) bounds the conditional volatility of the permanent component in the same units as $J$. Inequality (2.8) bounds the unconditional volatility of the permanent component relative to the one of the stochastic discount factor, and hence it is similar to the variance ratio used in Cochrane (1988).

To better understand the measure of volatility $J(x)$, note that if $\operatorname{var}(x)=0$, then $J(x)=$ 0 ; the reverse is not true, as higher-order moments than the variance also affect $J(x)$. More specifically, the variance and $J(x)$ are special cases of the general measure of volatility $f(E x)-$ $E f(x)$, where $f(\cdot)$ is a concave function. The statistic $J(x)$ is obtained by making $f(x)=\log x$, while for the variance, $f(x)=-x^{2}$. It follows that if a random variable $x_{1}$ is more risky than $x_{2}$ in the sense of Rothschild-Stiglitz, then $J\left(x_{1}\right) \geq J\left(x_{2}\right)$ and, of course, $\operatorname{var}\left(x_{1}\right) \geq \operatorname{var}\left(x_{2}\right){ }^{6}$ As a special case, if $x$ is lognormal, then $J(x)=1 / 2 \operatorname{var}(\log x)$.

\footnotetext{
${ }^{6}$ Recall that $x_{1}$ is more risky than $x_{2}$ in the sense of Rothschild and Stiglitz if, for $E\left(x_{1}\right)=E\left(x_{2}\right), E\left(f\left(x_{1}\right)\right) \leq$ $E\left(f\left(x_{2}\right)\right)$ for any concave function $f$.
} 
The next example illustrates Proposition 3 for the case where the two components are lognormal with arbitrary correlation. In logs the permanent component is a random walk with drift and the transitory component is covariance stationary. This type of process has often been used in the measurement of the size of the permanent component for linear time series. See, for instance, Watson (1986) and Cochrane (1988). In this case, it is easy to check that the regularity condition for the scaled covariance (2.6) is satisfied. Moreover, as explained above, the $J^{\prime} s$ are replaced by one half the variance of the $\log$.

Example 4 Assume that

$$
\begin{aligned}
& \log M_{t+1}^{P}=\log M_{t}^{P}-\frac{1}{2} \sigma_{P}^{2}+\varepsilon_{t+1}^{P} \\
& \log M_{t+1}^{T}=\sum_{i=0}^{\infty} \alpha_{i} \varepsilon_{t+1-i}^{T}+(t+1) \log \beta
\end{aligned}
$$

where $\alpha$ is a square summable sequence, and $\varepsilon_{t+1}^{P}$ and $\varepsilon_{t+1}^{T}$ are i.i.d. normal with zero mean, variance $\sigma_{P}^{2}$ and $\sigma_{T}^{2}$ respectively, and with arbitrary covariance $\sigma_{T P}$. Direct computation gives

$$
\log \frac{\left(1+v_{t+1, t+k}\right)}{\left(1+v_{t, t+k}\right)}=-\alpha_{k-1} \sigma_{T P}
$$

hence, (2.3) is satisfied, since $\lim _{k \rightarrow \infty} \alpha_{k-1}=0$ because $\alpha$ is square summable. Furthermore,

$$
J_{t}\left(\frac{M_{t+1}^{P}}{M_{t}^{P}}\right)=\frac{1}{2} \sigma_{P}^{2} \geq E_{t} \log \frac{R_{t+1}}{R_{t+1,1}}-h_{t}(\infty)
$$

and

$$
\frac{J\left(\frac{M_{t+1}^{P}}{M_{t}^{P}}\right)}{J\left(\frac{M_{t+1}}{M_{t}}\right)}=\frac{\sigma_{P}^{2}}{\operatorname{var}\left(\log \frac{M_{t+1}}{M_{t}}\right)} \geq \frac{E\left[\log \frac{R_{t+1}}{R_{t+1,1}}\right]-E\left[h_{t}(\infty)\right]}{E\left[\log \frac{R_{t+1}}{R_{t+1,1}}\right]+\frac{1}{2} \sigma_{\log R_{t+1,1}}^{2}},
$$

where $\sigma_{\log R_{t+1,1}}^{2}$ denotes the log of the one-period interest rate.

The following proposition establishes the existence of a decomposition of the pricing kernel into a transitory component, satisfying (2.3), and a permanent component that is a martingale. We make the following assumption on $\left\{M_{t}\right\}$. First, (i) there is a number $\beta$ such that

$$
0<\lim _{k \rightarrow \infty} V_{t}\left(1_{t+k}\right) / \beta^{k}<\infty
$$

all $t$, where $V_{t}\left(1_{t+k}\right)=E_{t}\left[M_{t+k} / M_{t}\right]$ is the price of a $k$-period zero-coupon bond. Second, (ii) that for each $t+1$, there is a random variable $x_{t+1}$ such that

$$
\left(M_{t+1} / \beta^{t+1}\right) V_{t+1}\left(1_{t+k}\right) / \beta^{k} \leq x_{t+1},
$$

with $E_{t} x_{t+1}$ finite for all $k$. Finally, (iii) we assume that $\lim _{s \rightarrow \infty} \beta^{s} / V_{t}\left(1_{t+s}\right)$ has no permanent innovations, that is, (2.3) holds. 
Proposition 5 Under assumptions (i), (ii) and (iii), a decomposition $M_{t}=M_{t}^{T} M_{t}^{P}$, with $E_{t} M_{t+1}^{P}=$ $M_{t}^{P}$ and $M_{t}^{T}$ having no permanent innovations exist, with

$$
M_{t}^{P}=\lim _{k \rightarrow \infty} E_{t} M_{t+k} / \beta^{t+k} .
$$

Assumption (i) and (ii) are regularity conditions. Assumption (iii), roughly speaking, requires interest rates to be stationary. The existence result in proposition (5) is an analog to the one in Beveridge and Nelson (1981). There are two main differences between our decomposition and Beveridge and Nelson's: in our case, the permanent component is a martingale as opposed to a random walk, and the decomposition is multiplicative instead of additive. Condition (iii) above is the analog of the assumption in the Beveridge and Nelson (1981) that the process be difference stationary.

Following Cochrane and Hansen (1992, pp 134-137) one can derive the following lower bound on the fraction of the variance of the stochastic discount factor accounted for by its innovations:

$$
\frac{E\left[\operatorname{var}_{t}\left(\frac{M_{t+1}}{M_{t}}\right)\right]}{\operatorname{var}\left(\frac{M_{t+1}}{M_{t}}\right)} \geq 1-\frac{1}{\left(\frac{E\left|R_{t+1}-R_{t+1,1}\right|}{\sigma\left(R_{t+1}\right)}\right)^{2}} \frac{\operatorname{var}\left[V_{t}\left(1_{t+1}\right)\right]}{\left(E\left[V_{t}\left(1_{t+1}\right)\right]\right)^{2}}
$$

for any return $R_{t+1}$. This lower bound takes a value of about 0.99 when $R_{t+1}$ is an asset with a Sharp ratio of 0.5 and one-period interest volatility is low, such as $\operatorname{var}\left[V_{t}\left(1_{t+1}\right)\right]=0.05^{2}$. Although informative about some aspects of persistence, one-period interest rates with low volatility are consistent with any size of the permanent component of the pricing kernel. For instance, a pricing kernel with no permanent innovations can still have one-period interest rates with arbitrary small variance.

(i) Yields and forward rates: Alternative measures of term spreads For empirical implementation, we want to be able to extract as much information from long-term bond data as possible. For that reason, we show here that for asymptotic zero-coupon bonds, the unconditional expectations of the yields and the forward rates are equal to the unconditional expectations of the holding returns.

Consider forward rates. The $k$-period forward rate differential is defined as the rate for a one-period deposit maturing $k$ periods from now relative to a one-period deposit now:

$$
f_{t}(k) \equiv-\log \left(\frac{V_{t}\left(1_{t+k}\right)}{V_{t}\left(1_{t+k-1}\right)}\right)-\log \frac{1}{V_{t, 1}} .
$$

Forward rates and expected holding returns are also closely related. They both compare prices of bonds with a one-period maturity difference, the forward rate does it for a given $t$, while 
the holding return considers two periods in a row. Assuming that bond prices have means that are independent of calendar time, so that $E V_{t}\left(1_{t+k}\right)=E V_{\tau}\left(1_{\tau+k}\right)$ for every $t$ and $k$, then, it is immediate that $E\left[h_{t}(k)\right]=E\left[f_{t}(k)\right]$.

We define the continuously compounded yield differential between a $k$-period discount bond and a one-period risk-free bond as

$$
y_{t}(k) \equiv \log \left(\frac{V_{t}\left(1_{t+1}\right)}{V_{t}\left(1_{t+k}\right)^{1 / k}}\right) .
$$

The next proposition shows that under regularity conditions, the three measures of the term spreads are equal for the limiting zero-coupon bonds.

Proposition 6 If the limits of $h_{t}(k), f_{t}(k)$, and $y_{t}(k)$ exist, the unconditional expectations of holding returns are independent of calendar time; that is,

$$
E\left[\log R_{t+1, k}\right]=E\left[\log R_{\tau+1, k}\right] \text { for all } t, \tau, k
$$

and holding returns and yields are dominated by an integrable function, then

$$
E\left[\lim _{k \rightarrow \infty} h_{t}(k)\right]=E\left[\lim _{k \rightarrow \infty} f_{t}(k)\right]=E\left[\lim _{k \rightarrow \infty} y_{t}(k)\right] .
$$

In practice, these three measures may not be equally convenient to estimate for two reasons. One is that the term premium is defined in terms of the conditional expectation of the holding returns. But this will have to be estimated from ex post realized holding returns, which are very volatile. Forward rates and yields are, according to the theory, conditional expectations of bond prices. While forward rates and yields are more serially correlated than realized holding returns, they are substantially less volatile. Overall, they should be more precisely estimated. The other reason is that, while results are derived for the limiting maturity, data is available only for finite maturities. All the previous results could have been derived for a finite $k$ by assuming that limiting properties are reached at maturity $k$, except Proposition 6. In these cases, yields are equal to averages of forward rates (or holding returns), and the average only equals the last element in the limit. For this reason, yield differentials, $y$, might be slightly less informative for $k$ finite than the term spreads estimated from forward rates and holding returns.

\section{Empirical Evidence}

The main objective of this section is to estimate a lower bound for the size of the permanent component of pricing kernels. We also present two additional results that help interpreting these 
estimates. First, we present a simple example of a process for pricing kernels. Second, we measure the part of the permanent component due to inflation.

\section{A. The size of the permanent component}

We estimate the lower bound of the size of the permanent component of pricing kernels derived in Proposition 3:

$$
\frac{J\left(\frac{M_{t+1}^{P}}{M_{t}^{P}}\right)}{J\left(\frac{M_{t+1}}{M_{t}}\right)} \geq \frac{E\left[\log \frac{R_{t+1}}{R_{t+1,1}}\right]-E\left[h_{t}(\infty)\right]}{E\left[\log \frac{R_{t+1}}{R_{t+1,1}}\right]+J\left(1 / R_{t+1,1}\right)}
$$

Tables 1, 2, and 3 contain the estimates of the right-hand side of (3.1) obtained by replacing each expected value with its sample analog for different data sets.

In Table 1, we report estimates of the lower bound given in equation (3.1), of each of the three quantities entering into it, its numerator and the p-value that the numerator is negative. We present estimates using zero-coupon bonds for maturities 25 and 29 years, for various measures of the term spread (based on yields, forward rates and holding returns), and for holding periods of one year and one month. As return $R_{t+1}$ we use the CRSP value-weighted index covering the NYSE, Amex and NASDAQ. The data is monthly, from 1946:12 to 1999:12. Standard errors of the estimated quantities are presented in parentheses; for the size of the permanent component, we use the delta method. The variance-covariance of the estimates is computed by using a Newey and West (1987) window with 36 lags to account for the overlap in returns and the persistence of the different measures of the spreads. ${ }^{7}$

The asymptotic probability that the term spread is larger than the log equity premium is very small, in most cases well below 1\%. Hence, as implied by Proposition (2) the hypothesis that the pricing kernel has no permanent innovation is clearly rejected. Not only is there a permanent component, it is very large. We find that the lower bound of the size of the permanent component is about 100\%; none of our estimates are below $75 \%$. The estimates are precise, standard errors are below 10\%, except for holding returns.

\footnotetext{
${ }^{7}$ For maturities longer than 15 years, we do not have a complete data set for zero-coupon bonds. In particular, long-term bonds have not been consistently issued during this period. For instance, for zero- coupon bonds maturing in 29 years, we have data for slightly more than half of the sample period, with data missing at the beginning and in the middle of our sample. The estimates of the various expected values on the right-hand side of (3.1) are based on different numbers of observations. We take this into account when computing the variancecovariance of our estimators. Our procedure gives consistent estimates as long as the periods with missing bond data are not systematically related to the magnitudes of the returns.
} 
Two points about the result in Table 1 are noteworthy. First, the choice of the holding period, and hence the level of the risk-free rate, has some effects on our estimates. For instance, using yields with a yearly holding period the size of the permanent component is estimated to be about $87 \%$. Instead, using yields and a monthly holding period we estimate it to be $77 \%$. This difference is due, mainly, to the fact that monthly yields are about $1 \%$ below annual yields, affecting the estimate of the denominator of the lower bound. ${ }^{8}$ Second, by estimating the right-hand side of equation (3.1) as the ratio of sample means, our estimates are consistent but biased in small samples because the denominator has nonzero variance. In Appendix C, we present estimates of this bias. They are quantitatively negligible, on the order of about $1 \%$ in absolute value terms.

Since (3.1) holds for any return $R_{t+1}$, we select portfolios with high $E\left[\log \frac{R_{t+1}}{R_{t+1,1}}\right]$ in Table 2 to sharpen the bounds based on the equity premium in Table 1. Table 2 contains the same information as Table 1, except that Table 2 covers only bonds with 25 years of maturity. We find estimates of $E\left[\log \frac{R_{t+1}}{R_{t+1,1}}\right]$ of up to $22.5 \%$ compared to $7.6 \%$ in Table 1 . The smallest estimate of the lower bound in Table 2 is $89 \%$ as opposed to $77 \%$ in Table 1.

As a benchmark case, panel A reproduces the results of Table 1 . In panel B we let $R_{t+1}$ be a fixed weight portfolio of aggregate equity with the risk-free that maximizes $E\left[\log \frac{R_{t+1}}{R_{t+1,1}}\right]$. Depending on the choice of the holding period, $E\left[\log \frac{R_{t+1}}{R_{t+1,1}}\right]$ is up to $9 \%$ larger than the premium presented in panel $\mathrm{A}$, with a share of equity of 2.14 or 3.47. In panel $\mathrm{C}$, we choose a fixed-weight portfolio from the menu of the 10 CRSP size decile portfolios. This leads to a log excess return of up to $22.5 \%$.

Table 3 extends the sample period to over 100 years and adds an additional country, the U.K. For the U.S., given data availability, we use coupon bonds with about 20 years of maturity. For the U.K., we use consols. For the U.S., we estimate the size of the permanent component between $78 \%$ and $93 \%$, depending on the time period and whether we consider the term premium or the yield differential. Estimated values for the U.K. are similar to those for the U.S.

A natural concern is whether 25- or 29-year bonds allow for good approximations of the limiting term spread, $E\left[h_{t}(\infty)\right]$. From Figure 1, which plots term structures for three definitions of term spreads, we take that the long end of the term structure is either flat or decreasing. Extrapolating from these pictures, suggests, if anything, that our estimates of the size of the permanent component presented in Tables 1 and 2 are on the low side. In this figure, the

\footnotetext{
${ }^{8}$ Our data set does not contain the information necessary to present results for monthly holding periods for forwards rates and holding returns.
} 
standard error bands are wider for longer maturities, which is due to two effects. One is that spreads on long-term bonds are more volatile, especially for holding returns. The other is that for longer maturities, as discussed before, our data set is smaller.

Note that for the bound in Equation (3.1) to be well defined, specifically for $J\left(1 / R_{t+1,1}\right)$ to be finite, we have assumed that interest rates are stationary. ${ }^{9}$ While the assumption of stationary interest rates is confirmed by many studies (for instance, Ait Sahalia (1996)), others report the inability to reject unit roots (for instance, Hall, Anderson, and Granger (1992)). To some extent, if interest rates were nonstationary, this would seem to further support the idea that the pricing kernel itself is nonstationary. Also, consistent with the idea that interest rates are stationary and therefore $J\left(1 / R_{t+1,1}\right)$ finite, Table 3 shows lower estimates for the very long samples than for the postwar period.

\section{B. An example of a pricing kernel}

We present here an example that illustrates the power of bond data to distinguish between similar levels of persistence. In particular, the example shows that even for bonds with maturities between 10 and 30 years, one can obtain strong implications for the degree of persistence. Alternatively, the example shows that, in order to explain the low observed term premia for long-term bonds at finite maturities with a stationary pricing kernel, the largest root has to be extremely close to 1 .

Assume that

$$
\log M_{t+1}=\log \beta+\rho \log M_{t}+\varepsilon_{t+1}
$$

with $\varepsilon_{t+1} \sim N\left(0, \sigma_{\varepsilon}^{2}\right)$. Simple algebra shows that

$$
h_{t}(k)=\frac{\sigma_{\varepsilon}^{2}}{2}\left(1-\rho^{2(k-1)}\right) .
$$

This expression suggests that if the volatility of the innovation of the pricing kernel, $\sigma_{\varepsilon}^{2}$, is large, then values of $\rho$ only slightly below 1 may have a significant quantitative effect on the term spread. In Table 4, we calculate the level of persistence, $\rho$, required to explain various levels of term spreads for discount bonds with maturities of 10, 20, and 30 years. As is clear from Table 4, $\rho$ has to be extremely close to 1 .

\footnotetext{
${ }^{9}$ Equation (2.7), which defines a bound for the size of the permanent component in absolute terms, does not require this assumption.
} 
For this calculation we have set $\sigma_{\varepsilon}^{2}=0.4$, for the following reasons. Based on Proposition 3 and assuming lognormality, we get

$$
\operatorname{var}\left(\log \frac{M_{t+1}}{M_{t}}\right) \geq 2 \cdot E \log \frac{R_{t+1}}{R_{t+1,1}}+\operatorname{var}\left(\log R_{t+1,1}\right),
$$

where $R_{t+1}$ can be any risky return. Based on our estimates in Table 2 , the growth optimal excess return should be at least $20 \%$, so that $\operatorname{var}\left(\log \frac{M_{t+1}}{M_{t}}\right) \geq 0.4$. Finally, for $\rho$ close to 1 we can write

$$
\operatorname{var}\left(\log \frac{M_{t+1}}{M_{t}}\right)=\frac{2}{1+\rho} \sigma_{\varepsilon}^{2} \simeq \sigma_{\varepsilon}^{2}
$$

C. Nominal versus real pricing kernels

Because we have so far used bond data for nominal bonds, we have implicitly measured the size of the permanent component of nominal pricing kernels, that is, the processes that price future dollar amounts. We present now two sets of evidence showing that the permanent component is to a large extent real, so that we have a direct link between the size of the permanent component of pricing kernels and real economic fundamentals.

First, assume, for the sake of this argument, that all of the permanent movements in the (nominal) pricing kernel come from the aggregate price level. Specifically, assume that $M_{t}=$ $\left(\frac{1}{P_{t}}\right) M_{t}^{T}$, where $P_{t}$ is the aggregate price level. Thus $\frac{1}{P_{t}}$ converts nominal payouts into real payouts and $M_{t}^{T}$ prices real payouts. Because, $P_{t}$ is directly observable, we can measure the size of its permanent component directly and then compare it to the estimated size of the permanent component of pricing kernels reported in Tables 1, 2, and 3. It turns out that the size of the permanent component in $P_{t}$ is estimated at up to 100 times smaller than the lower bound of the size of the permanent component in pricing kernels estimated above. This suggests that movements in the aggregate price level have a minor importance in the permanent component of pricing kernels, and thus, permanent components in pricing kernels are primarily real.

The next proposition shows how to estimate the size of the permanent component based on the $J($.$) measure.$

Proposition 7 Assume that the process $X_{t}$ can be decomposed into a permanent component $X_{t}^{P}>0$ and a transitory component $X_{t}^{T}>0$, so that (i)

$$
X_{t}=X_{t}^{P} X_{t}^{T}
$$


(ii) the permanent component is a martingale, that is, $E_{t}\left[X_{t+1}^{P}\right]=X_{t}^{P}$ for all $t$, (iii) the process $X_{t}^{T}$ has no permanent innovations, that is,

$$
\lim _{k \rightarrow \infty} E_{t} \log \frac{E_{t+1} X_{t+k}^{T}}{E_{t} X_{t+k}^{T}}=0 .
$$

Additionally, assume the following regularity conditions: (a) the covariance between $X_{t}^{T}$ and $X_{t}^{P}$ stabilizes, that is,

$$
\lim _{k \rightarrow \infty} E_{t}\left[\log \frac{\left(1+v_{t+1, t+k}\right)}{\left(1+v_{t, t+k}\right)}\right]=0 \text { almost surely }
$$

with $v_{t, t+k}$ defined as $v_{t, t+k} \equiv \operatorname{cov}_{t}\left[X_{t+k}^{T}, X_{t+k}^{P}\right] /\left[E_{t} X_{t+k}^{T} E_{t} X_{t+k}^{P}\right]$, (b) $\frac{X_{t+1}}{X_{t}}$ is strictly stationary, (c) the following limit exists:

$$
\lim _{k \rightarrow \infty} E\left[\log E_{t}\left[\frac{X_{t+k}}{X_{t}}\right]-\log E_{t}\left[\frac{X_{t+k-1}}{X_{t}}\right]\right]
$$

and (d) $\lim _{k \rightarrow \infty} \frac{1}{k} J\left(\frac{E_{t} X_{t+k}}{X_{t}}\right)=0$. Then

$$
J\left(\frac{X_{t+1}^{P}}{X_{t}^{P}}\right)=\lim _{k \rightarrow \infty} \frac{1}{k} J\left(\frac{X_{t+k}}{X_{t}}\right) .
$$

The usefulness of this proposition is that $J\left(X_{t+1}^{P} / X_{t}^{P}\right)$ is a natural measure for the size of the permanent component. However, it cannot directly be estimated if only $X_{t}$ is observable, but $X^{P}$ and $X^{T}$ are not observable separately. The quantity $\lim _{k \rightarrow \infty} \frac{1}{k} J\left(X_{t+k} / X_{t}\right)$ can be estimated with knowledge of only $X_{t}$. This result is analogous to a result in Cochrane (1988), with a main difference that he uses the variance as a measure of volatility.

Cochrane (1988) proposes a simple method for correcting for small sample bias and for computing standard errors when using the variance as a measure of volatility. Thus, we will focus our presentation of the results on the variance, having established first that, without adjusting for small sample bias, the variance equals approximately one-half of the $J($.$) estimates, which$ would suggest that departures from lognormality are small. Overall, we estimate the size of the permanent component of inflation to be below $0.5 \%$ based on data for 1947-99 and below $0.8 \%$ based on data for 1870-1999. This compares to the lower bound of the (absolute) size of the permanent component of the pricing kernel,

$$
J\left(\frac{M_{t+1}^{P}}{M_{t}^{P}}\right) \geq E\left[\log \frac{R_{t+1}}{R_{t+1,1}}-h_{t}(\infty)\right],
$$

that we have estimated to be up to about $20 \%$ as reported in column 5 in Tables 1 , 2, and 3 . 
Table 5 contains our estimates of the permanent component of inflation. The first two rows display results based on estimating an AR1 or AR2 for inflation and then computing the size of the permanent component as one-half of the (population) spectral density at frequency zero. For the postwar sample, $1947-99$, we find $0.21 \%$ and $0.15 \%$ for the AR1 and AR2, respectively. The third row presents the results using Cochrane's (1988) method that estimates $\operatorname{var}\left(\log X_{t+1}^{P} / X_{t}^{P}\right)$ using $\lim _{k \rightarrow \infty}(1 / k) \operatorname{var}\left(\log X_{t+k} / X_{t}\right)$. For the postwar period, the size of the permanent component is $0.43 \%$ or $0.30 \%$, depending on whether $k=20$ or $30 .{ }^{10}$ The table also shows that $J\left(X_{t+k} / X_{t}\right) / \operatorname{var}\left(\log X_{t+k} / X_{t}\right)$ is approximately 0.5. Note that the roots of the process for inflation reported in Table 5 are far from one, supporting our implicit assumption that inflation rates are stationary.

A second view about the size of the permanent component can be obtained from inflationindexed bonds. Such bonds have been traded in the U.K. since 1982. Considering that an inflation-indexed bond represents a claim to a fixed number of units of goods, its price provides direct evidence about the real pricing kernel. However, because of the 8-month indexation lag for U.K. inflation-indexed bonds, it is not possible to obtain much information about the short end of the real term structure. Specifically, an inflation-indexed bond with outstanding maturity of less than eight months is effectively a nominal bond. For our estimates, this implies that we will not be able to obtain direct evidence of $E\left(\log R_{t+1,1}\right)$ and $J\left(1 / R_{t+1,1}\right)$ in the definition of the size of the permanent component as given in equation (2.8). Because of this, we focus on the bound for the absolute size of the pricing kernel as given in equation (3.4). For the nominal kernel, we use average nominal equity returns for $E \log R_{t+1}$, and for $E \log R_{t+1, \infty}$, we use forward rates and yields for 20 and 25 years, from the Bank of England's estimates of the zero-coupon term structures, to obtain an estimate of the right-hand side of

$$
J\left(\frac{M_{t+1}^{P}}{M_{t}^{P}}\right) \geq E\left[\log R_{t+1}-\log R_{t+1, \infty}\right] .
$$

For the real kernel, we take the average nominal equity return minus the average inflation rate to get $E \log R_{t+1}$; for $E \log R_{t+1, \infty}$, we use real forwards rates and yields from a zero-coupon term structure of inflation-indexed bonds. The right-hand side of (3.5) differs for nominal and real pricing kernels only if there is an inflation risk premium for long-term nominal bonds. If long-term nominal bonds have a positive inflation risk premium then the lower bound for the

\footnotetext{
${ }^{10}$ Cochrane's (1988) estimator is defined as $\widehat{\sigma}_{k}^{2}=\frac{1}{k}\left(\frac{1}{T-k}\right)\left(\frac{T}{T-k+1}\right) \cdot \sum_{j=k}^{T}\left[x_{j}-x_{j-k}-\frac{k}{T}\left(x_{T}-x_{0}\right)\right]^{2}$, with $T$ the sample size, $x=\log X$, and standard errors given by $\left(\frac{4}{3} \frac{k}{T}\right)^{0.5} \widehat{\sigma}_{k}^{2}$.
} 
permanent component for real kernels will be larger than for nominal kernels.

Table 6 reports estimates for nominal and real kernels. The data are further described in Appendix B. Consistent with our finding that the size of the permanent component of inflation is very small, the differences in size of the permanent components for nominal and real kernels are very small. Comparing columns (3) and (6), for three out of the four point estimates, the size of the permanent component of real kernels is larger than the estimate for the corresponding nominal kernels; for the fourth case, they are basically identical. The corresponding standard errors are always larger than the differences between the results for nominal and real kernels.

\section{Pricing Kernels and Aggregate Consumption}

In many models used in the literature, the pricing kernel is a function of current or lagged consumption. Thus, the stochastic process for consumption is a determinant of the process of the pricing kernel. In this section, we present sufficient conditions on consumption and the function mapping consumption into the pricing kernel so that pricing kernels have no permanent innovations. We are able to define a large class of stochastic processes for consumption that, combined with standard preference specifications, will result in counterfactual asset pricing implications. We also present an example of a utility function in which the resulting pricing kernels have permanent innovations because of the persistence introduced through the utility function. Finally, we estimate the size of the permanent component in consumption directly and compare it to our estimates of the size of the permanent component of pricing kernels.

As a starting point, we present sufficient conditions for kernels that follow Markov processes to have no permanent innovations. We then consider consumption within this class of processes. Assume that

$$
M_{t}=\beta(t) f\left(s_{t}\right),
$$

where $f$ is a positive function and that $s_{t} \in S$ is Markov with transition function $Q$ which has the interpretation $\operatorname{Pr}\left(s_{t+1} \in A \mid s_{t}=s\right)=Q(s, A)$.

We assume that $Q$ has an invariant distribution $\lambda^{*}$ and that the process $\left\{s_{t}\right\}$ is drawn at time $t=0$ from $\lambda^{*}$. In this case, $s_{t}$ is strictly stationary, and the unconditional expectations are taken with respect to $\lambda^{*}$. We use the standard notation,

$$
\left(T^{k} f\right)(s) \equiv \int_{S} f\left(s^{\prime}\right) Q^{k}\left(s, d s^{\prime}\right)
$$


where $Q^{k}$ is the $k$-step ahead transition constructed from $Q$.

Proposition 8 Assume that there is a unique invariant measure, $\lambda^{*}$, and that

$$
\frac{\left(T^{k-1} f\right)\left(s^{\prime}\right)}{\left(T^{k} f\right)(s)} \geq l>0 \text { for all } k \text {. }
$$

In addition, if either (i) $\lim _{k \rightarrow \infty}\left(T^{k} f\right)(s)=\int f d \lambda^{*}>0$ or, in case $\lim _{k \rightarrow \infty}\left(T^{k} f\right)(s)$ is not finite, if (ii) $\lim _{k \rightarrow \infty}\left[\left(T^{k-1} f\right)\left(s^{\prime}\right)-\left(T^{k} f\right)(s)\right] \leq A(s)$ for each $s$ and $s^{\prime}$, then

$$
\lim _{k \rightarrow \infty} E_{t} \log \frac{E_{t+1}\left[M_{t+k}\right]}{E_{t}\left[M_{t+k}\right]}=0 .
$$

Remark 1 The uniform lower bound, l, is stronger than the strict positivity implied by noarbitrage. This bound is needed to pass the limit through the conditional expectation operator.

We are now ready to consider consumption explicitly. Assume that

$$
C_{t}=\tau(t) c_{t}=\tau(t) g\left(s_{t}\right)
$$

where $g$ is a positive function, $s_{t} \in S$ is Markov with transition function $Q$, and $\tau(t)$ represents a deterministic trend. We assume (a) that a unique invariant measure $\lambda^{*}$ exists. Furthermore, assume (b) that

$$
\lim _{k \rightarrow \infty}\left(T^{k} h\right)(s)=\int h d \lambda^{*}
$$

for all $h($.$) bounded and continuous.$

Proposition 9 Assume that $M_{t}=\beta(t) f\left(c_{t}, x_{t}\right)$, with $f(\cdot)$ positive, bounded and continuous, and that $\left(c_{t}, x_{t}\right) \equiv s_{t}$ satisfies properties (a) and (b) with $f(\cdot)>0$ with positive probability. Then $M_{t}$ has no permanent innovations.

An example covered by this proposition is CRRA utility, $\frac{1}{1-\gamma} c_{t}^{1-\gamma}$ with relative risk aversion $\gamma$, where $f\left(c_{t}\right)=c_{t}^{-\gamma}$, with $\bar{c} \geq c_{t} \geq \varepsilon>0$. If consumption would have a unit root, then properties (a) and (b) would not be satisfied.

For the CRRA case, even with consumption satisfying properties (a) and (b), Proposition (9) could fail to be satisfied because $c_{t}^{-\gamma}$ is unbounded if $c_{t}$ gets arbitrarily close to zero with large enough probability. It is possible to construct examples where this is the case, for instance, along the lines of the model in Aiyagari (1994). This outcome is driven by the Inada condition $u^{\prime}(0)=\infty$. Note also, the bound might not be necessary. For instance, if $\log c_{t}=\rho \log c_{t-1}+\varepsilon_{t}$, with $\varepsilon \sim N\left(0, \sigma^{2}\right)$ and $|\rho|<1$, then, $\log f\left(c_{t}\right)=-\gamma \log c_{t}$, and direct calculations show that condition (2.3) defining the property of no permanent innovations is satisfied. 
A. Examples with additional state variables

There are many examples in the literature for which marginal utility is a function of additional state variables, and for which it is straightforward to apply Proposition 9, very much like for the CRRA utility shown above. For instance, the utility functions displaying various forms of habits such as those used by Ferson and Constantinides (1991), Abel (1999) and Campbell and Cochrane (1999). On the other hand, there are cases where Proposition 9 does not apply. For instance, as we show below, for the Epstein-Zin-Weil utility function. In this case, even with consumption satisfying the conditions required for Proposition 9, the additional state variable does not have an invariant distributions. Thus, innovations to pricing kernels have always permanent effects.

Assume the representative agent has preferences represented by nonexpected utility of the following recursive form:

$$
U_{t}=\phi\left(c_{t}, E_{t} U_{t+1}\right)
$$

where $U_{t}$ is the utility starting at time $t$ and $\phi$ is an increasing concave function. Epstein and Zin (1989) and Weil (1990) develop a parametric case in which the risk aversion coefficient, $\gamma$, and the reciprocal of the elasticity of intertemporal substitution, $\rho$, are constant. They also characterize the stochastic discount factor $M_{t+1} / M_{t}$ for a representative agent economy with an arbitrary consumption process $\left\{C_{t}\right\}$ as

$$
\frac{M_{t+1}}{M_{t}}=\left[\beta\left(\frac{C_{t+1}}{C_{t}}\right)^{-\rho}\right]^{\theta}\left[\frac{1}{R_{t+1}^{c}}\right]^{(1-\theta)}
$$

with $\theta=(1-\gamma) /(1-\rho)$ where $\beta$ is the time discount factor and $R_{t+1}^{c}$ the gross return on the consumption equity, that is the gross return on an asset that pays a stream of dividends equal to consumption $\left\{C_{t}\right\}$.

Inspection of (4.1) reveals that a pricing kernel $M_{t+1}$ for this model is

$$
M_{t+1}=\beta^{\theta(t+1)} Y_{t+1}^{\theta-1} C_{t+1}^{-\rho \theta}, \text { where } Y_{t+1}=R_{t+1}^{c} \cdot Y_{t}
$$

and $Y_{0}=1$.

The next proposition shows that the nonseparabilities that characterize these preferences for $\theta \neq 1$ are such that, even if consumption is iid, the pricing kernel has permanent innovations. More precisely, assume that consumption satisfies

$$
C_{t}=\tau^{t} c_{t}
$$


where $c_{t} \in[\underline{c}, \bar{c}]$ is iid with $\operatorname{cdf} F$. Let $V_{t}^{c}$ be the price of the consumption equity, so that $R_{t+1}^{c}=\left(V_{t+1}^{c}+C_{t+1}\right) / V_{t}^{c}$. We assume that agents discount the future enough so as to have a well-defined price-dividend ratio. Specifically, we assume that

$$
\max _{c \in[\underline{c}, \bar{c}]} \beta \tau^{1-\rho}\left\{\int\left(\frac{c^{\prime}}{c}\right)^{1-\gamma} d F\left(c^{\prime}\right)\right\}^{1 / \theta}<1 .
$$

Proposition 10 Let the pricing kernel be given by (4.2), let the detrended consumption be iid as in (4.3), and assume that (4.4) holds. Then the price-dividend ratio for the consumption equity is given by $V_{t}^{c} / C_{t}=\psi c_{t}^{\gamma-1}$ for some constant $\psi>0$; hence, $V_{t}^{c} / C_{t}$ is iid. Moreover,

$$
x_{t+1, k} \equiv \frac{E_{t+1} M_{t+k}}{E_{t} M_{t+k}}=\frac{\left(1+\frac{1}{\psi} c_{t+1}^{(1-\gamma)}\right)^{\theta-1}}{E_{t}\left\{\left(1+\frac{1}{\psi} c_{t+1}^{(1-\gamma)}\right)^{\theta-1}\right\}}
$$

thus the pricing kernel has permanent innovations, that is $E_{t} \log x_{t+1, k}<0$, iff $\theta \neq 1, \gamma \neq 1$, and $c_{t}$ has strictly positive variance.

Note that $\theta=1$ corresponds to the case in which preferences are given by time separable expected discounted utility; and hence, with iid consumption, the pricing kernel has only temporary innovations. Expression (4.5) also makes clear that for values of $\theta$ close to one, the size of the permanent component is small.

\section{B. The size of the permanent component in consumption}

We present here estimates of the size of the permanent component of consumption, obtained directly from consumption data. We end up drawing two conclusions. One is that the size of the permanent component in consumption is about half the size of the overall volatility of the growth rate, which is lower than our estimates of the size of the permanent component of pricing kernels. This suggests that, within a representative agent asset pricing framework, preferences should be such as to magnify the size of the permanent component in consumption. The other conclusion, as noted in Cochrane (1988) for the random walk component in GDP, is that standard errors for these direct estimates are large.

As in subsection C. for inflation, we use Cochrane's method based on the variance, since $J\left(X_{t+k} / X_{t}\right) / \operatorname{var}\left(\log X_{t+k} / X_{t}\right)$ is close to 0.5. Specifically, for $k$ up to 35, it lies between 0.47 and 0.49. Our estimates for $(1 / k) \operatorname{var}\left(\log X_{t+k} / X_{t}\right) / \operatorname{var}\left(\log X_{t+1} / X_{t}\right)$, with associated standard error bands, are presented in Figures 2 and 3 for the periods 1889-1997 and 1946-97, respectively. 
For the period 1889-1997, shown in Figure 2, the estimates stabilize at around 0.5 and 0.6 for $k$ larger than 15. For the postwar period, shown in Figure 3, standard error bands accommodate any possibly reasonable number.

\section{Conclusions}

The main contribution of this paper is to derive and estimate a lower bound for the size of the permanent component of asset pricing kernels. We find that the permanent component is about at least as volatile as the stochastic discount factor itself. This result is driven by the historically low yields on long-term bonds. These yields contain the market's forecasts for the growth rate of the marginal utility of wealth over the period corresponding to the maturity of the bond. We also relate the persistence of pricing kernels to the persistence of their determinants in standard models, notably consumption. We present sufficient conditions for consumption and preference specifications to imply a pricing kernel with no permanent innovations. We present evidence that the permanent component of pricing kernels is determined, to a large extent, by real as opposed to nominal factors. Finally, we present some evidence that the size of the permanent component in consumption is smaller than the permanent component in pricing kernels. Within a representative agent framework, this evidence points toward utility functions that magnify the size of the permanent component. 


\section{References}

Abel, Andrew B., 1999, Risk Premia and Term Premia in General Equilibrium, Journal of Monetary Economics 43(1): 3-33.

Ait-Sahalia, Yacine, 1996, Nonparametric Pricing of Interest Rate Derivative Securities, Econometrica 64(3): 527-60.

Aiyagari, Rao S., 1994, Uninsured Idioyncratic Risk and Aggregate Saving, Quarterly Journal of Economics, Vol. 109, Issue 3, 659-684.

Alvarez, Fernando, and Jermann, Urban J., 2000a, Using Asset Prices to Measure the Cost of Business Cycles, http://finance.wharton.upenn.edu/ jermann/research.html.

Alvarez, Fernando, and Jermann, Urban J., 2000b, Efficiency, Equilibrium, and Asset Pricing with Risk of Default, Econometrica 68(4): 775-97.

Alvarez, Fernando, and Jermann, Urban J., 2001, The Size of the Permanent Component of Asset Pricing Kernels, NBER working paper 8360.

Anderson, Nicole, and Sleath, John, 1999, New Estimates of the UK Real and Nominal Yield Curves, Quarterly Bulletin, Bank of England, November.

Bansal, Ravi, and Lehmann, Bruce N., 1997, Growth-Optimal Portfolio Restrictions on Asset Pricing Models, Macroeconomic Dynamics 1(2): 333-54.

Baxter, Marianne, and Crucini, Mario, 1995, Business Cycles and the Asset Structure of Foreign Trade, International Economic Review 36(4): 821-54.

Beveridge, Stephen, and Nelson, Charles R., 1981, A New Approach to Decomposition of Economic Time Series into Permanent and Transitory Components with Particular Attention to Measurement of the "Business Cycle," Journal of Monetary Economics 7(2): 151-74.

Bliss, Robert R., 1997, Testing Term Structure Estimation Methods, in Advances in Futures and Options Research, Vol. 9, Boyle, Phelim; Pennachi, George; and Ritchken, Peter, eds. Greenwich, Conn.: JAI Press, pp. 197-231.

Campbell, John Y., 1996, Understanding Risk and Return, Journal of Political Economy 104(2): 298-345. 
Campbell, John Y., and Cochrane, John H., 1999, By Force of Habit: A Consumption-Based Explanation of Aggregate Stock Market Behavior, Journal of Political Economy 107(2): $205-51$.

Campbell, Cynthia J.; Kazemi, Hossein B.; and Nanisetty, Prasad, 1999, Time-Varying Risk and Return in the Bond Market: A test of a New Equilibrium Pricing Model, Review of Financial Studies 12(3): 631-42.

Cochrane, John H., 1988, How Big Is the Random Walk in GNP? Journal of Political Economy 96(5): 893-920.

Cochrane, John, H. and Hansen, Lars P., Asset Pricing Exploration for Macroeconomics, NBER Macroeconomic Annual, 1992: 152-65.

Daniel, Kent D., and Marshall, David A., 2001, Consumption and Asset Returns at Short- and Long-Horizons, manuscript, Northwestern University, Evanston IL.

Dolmas, Jim, 1998, Risk Preferences and the Welfare Cost of Business Cycles, Review of Economic Dynamics 1(3): 646-76.

Duffie, Darrell, 1996, Dynamic Asset Pricing Theory, Princeton, N.J.: Princeton University Press.

Epstein, Larry G., and Zin, Stanley E., 1989, Substitution, Risk Aversion, and the Temporal Behavior of Consumption and Asset Returns: A Theoretical Framework, Econometrica 57(4): 937-69.

Evans, Martin D. D., 1998, Real Rates, Expected Inflation, and Inflation Risk Premia, Journal of Finance 53(1): 187-218.

Ferson, Wayne E., and Constantinides, George M., 1991, Habit Persistence and Durability in Aggregate Consumption: Empirical Tests, Journal of Financial Economics 29(2): 199-240.

Hall, Anthony D.; Anderson, Heather M.; and Granger, Clive W. J., 1992, A Cointegration Analysis of Treasury Bill Yields, Review of Economics and Statistics 74(1): 116-26.

Hamilton, James D., 1994, Time Series Analysis, Princeton, N.J.: Princeton University Press. 
Hansen, Gary D., 1997, Technical Progress and Aggregate Fluctuations, Journal of Economic Dynamics and Control 21(6): 1005-23.

Hansen, Lars Peter, and Jagannathan, Ravi, 1991, Implications of Security Market Data for Models of Dynamic Economies, Journal of Political Economy 99(2): 225-62.

Ibbotson Associates, 2000, Stocks, Bonds, Bills, and Inflation-1998 Yearbook, Chicago: Ibbotson Associates, Inc.

Kazemi, Hossein B., 1992, An Intertemporal Model of Asset Prices in a Markov Economy with a Limiting Stationary Distribution, Review of Financial Studies 5(1): 85-104.

Lettau, Martin and Ludvigson, Syndey, 2001, Understanding Trend and Cycle in Asset Values: Bull, Bears, and the Wealth Effect on Consumption, manuscript, Federal Reserve Bank of New York.

Luttmer, Erzo G. J., 1996, Asset Pricing in Economies with Frictions, Econometrica 64(6): $1439-67$.

McCulloch, J. Huston, and Kwon, Heon-Chul, 1993, U.S. Term Structure Data, 1947-1991, Working Paper 93-6, Ohio State University.

Nelson, Charles R., and Plosser, Charles I., 1982, Trend and Random Walks in Macroeconomic Time-Series: Some Evidence and Implications, Journal of Monetary Economics, 10(2): 13962.

Newey, Whitney K., and West, Kenneth D., 1987, A Simple, Positive Semi-definite, Heteroskedasticity and Autocorrelation Consistent Covariance Matrix, Econometrica 55(3): 703-8.

Quah, Danny, 1992, The Relative Importance of Permanent and Transitory Components: Identification and some Theoretical Bounds, Econometrica 60(1): 107-18.

Shiller, Robert, 1998, Annual Data on US Stock Market Prices, Dividends, Earnings, 1871present with Associated Interest Rate, Price Level and Consumption Data, http://www.econ.yale.edu/ shiller/data/chapt26.html.

Watson, Mark W., 1986, Univariate Detrending Methods with Stochastic Trends, Journal of Monetary Economics 18(1): 49-75. 


\section{Appendix A: Proofs}

Proposition 2. By definition,

$$
\begin{aligned}
h_{t}(\infty) & =\lim _{k \rightarrow \infty}\left\{E_{t}\left(\log \left[\frac{R_{t+1, k}}{R_{t+1,1}}\right]\right)\right\}=\lim _{k \rightarrow \infty}\left\{E_{t} \log \left[\left(\frac{\frac{E_{t+1}\left[M_{t+k}\right]}{M_{t+1}}}{\frac{E_{t}\left[M_{t+k}\right]}{M_{t}}} \frac{E_{t}\left[M_{t+1}\right]}{M_{t}}\right)\right]\right\} \\
& =\log E_{t}\left[M_{t+1}\right]-E_{t} \log M_{t+1}+\lim _{k \rightarrow \infty}\left\{E_{t} \log E_{t+1}\left[M_{t+k}\right]-\log E_{t}\left[M_{t+k}\right]\right\} .
\end{aligned}
$$

Without permanent innovations, we have,

$$
h_{t}(\infty)=\log E_{t}\left[\frac{M_{t+1}}{M_{t}}\right]-E_{t} \log \frac{M_{t+1}}{M_{t}}=-\log R_{t+1,1}-E_{t} \log \frac{M_{t+1}}{M_{t}}
$$

For any risky gross asset return $R_{t+1}$, we have that $1=E_{t}\left[R_{t+1} \frac{M_{t+1}}{M_{t}}\right]$, so that by taking $\operatorname{logs}$ on both sides and using Jensen's inequality

$$
-E_{t}\left[\log \left(\frac{M_{t+1}}{M_{t}}\right)\right] \geq E_{t}\left[\log \left(R_{t+1}\right)\right]
$$

Combining this expression with equation (A.1), we obtain the desired result.

Proposition 3. First note that

$$
\begin{aligned}
E_{t+1}\left[M_{t+k}\right] & =E_{t+1}\left[M_{t+k}^{T}\right] E_{t+1}\left[M_{t+k}^{P}\right]\left(1+\frac{\operatorname{cov}_{t+1}\left[M_{t+k}^{T}, M_{t+k}^{P}\right]}{E_{t+1}\left[M_{t+k}^{T}\right] E_{t+1}\left[M_{t+k}^{P}\right]}\right) \\
& =E_{t+1}\left[M_{t+k}^{T}\right] E_{t+1}\left[M_{t+k}^{P}\right]\left(1+v_{t+1, t+k}\right)
\end{aligned}
$$

and likewise

$$
E_{t}\left[M_{t+k}\right]=E_{t}\left[M_{t+k}^{T}\right] E_{t}\left[M_{t+k}^{P}\right]\left(1+v_{t, t+k}\right)
$$

Hence,

$$
\log \frac{E_{t+1}\left[M_{t+k}\right]}{E_{t}\left[M_{t+k}\right]}=\log \frac{E_{t+1}\left[M_{t+k}^{T}\right]}{E_{t}\left[M_{t+k}^{T}\right]}+\log \frac{E_{t+1}\left[M_{t+k}^{P}\right]}{E_{t}\left[M_{t+k}^{P}\right]}+\log \frac{\left(1+v_{t+1, t+k}\right)}{\left(1+v_{t, t+k}\right)} .
$$

Finally, given our hypothesis about $v_{t, t+k}$ we have that

$$
\begin{aligned}
h_{t}(\infty) & =E_{t}\left[\log E_{t}\left[M_{t+1}\right]-E_{t} \log M_{t+1}\right]+\lim _{k \rightarrow \infty}\left\{E_{t} \log \frac{E_{t+1}\left[M_{t+k}\right]}{E_{t}\left[M_{t+k}\right]}\right\} \\
& =E_{t}\left[\log E_{t}\left[M_{t+1}\right]-E_{t} \log M_{t+1}\right]+\lim _{k \rightarrow \infty}\left\{E_{t} \log \frac{E_{t+1}\left[M_{t+k}^{P}\right]}{E_{t}\left[M_{t+k}^{P}\right]}\right\} .
\end{aligned}
$$

Then using Proposition 2 and the fact that $M^{P}$ is a martingale equation (2.7) follows directly. We then use the result that $J\left(x_{t+1}\right)=E J_{t}\left(x_{t+1}\right)+J_{t}\left(E_{t} x_{t+1}\right)$, which can be derived through 
straightforward algebra. Equation (2.8) follows. The direction of the inequality is obtained by differentiating with respect to the term representing the growth-optimal return.

Proposition 5. $\mathrm{A}(1)$ guarantees that $0<M_{t}^{P}<\infty$. $\mathrm{A}(2)$ allows for the application of the Lebesque Dominated Convergence theorem, which yields that $E_{t} M_{t+1}^{P}=M_{t}^{P}$. Finally, $\mathrm{A}(3)$ guarantees that $M_{t}^{T}$ has no permanent innovations.

Proposition 6. By definition,

$$
h_{t}(\infty)-y_{t}(\infty)=\lim _{k \rightarrow \infty} E_{t} \log R_{t+1, k}-\lim _{k \rightarrow \infty}(1 / k) \sum_{j=1}^{k} \log R_{t+j, k-(j-1)} .
$$

Taking unconditional expectations on both sides, we have that

$$
E\left\{h_{t}(\infty)-y_{t}(\infty)\right\}=E \lim _{k \rightarrow \infty} E_{t} \log R_{t+1, k}-E \lim _{k \rightarrow \infty}(1 / k) \sum_{j=1}^{k} \log R_{t+j, k-(j-1)}
$$

Since by assumption expected holding returns and yields, $E_{t} \log R_{t+1, k}$ and $(1 / k) \sum_{j=1}^{k} \log R_{t+j, k-(j-1)}$, are dominated by an integrable random variable and the limit of the right-hand side exists, then by the Lebesgue dominated convergence theorem,

$$
\begin{aligned}
E \lim _{k \rightarrow \infty} E_{t} \log R_{t+1, k} & =\lim _{k \rightarrow \infty} E \log R_{t+1, k} \\
E \lim _{k \rightarrow \infty}(1 / k) \sum_{j=1}^{k} \log R_{t+j, k-(j-1)} & =\lim _{k \rightarrow \infty}(1 / k) \sum_{j=1}^{k} E \log R_{t+j, k-(j-1)} .
\end{aligned}
$$

Denote the limit

$$
\lim _{k \rightarrow \infty} E \log R_{t+1, k}=r,
$$

which we assume to be finite. Since, by hypothesis, $E \log R_{t+j, k-(j-1)}=E \log R_{t+1, k-(j-1)}$ for all $j$, then

$$
\lim _{k \rightarrow \infty}(1 / k) \sum_{j=1}^{k} E \log R_{t+j, k-(j-1)}=\lim _{k \rightarrow \infty}(1 / k) \sum_{j=1}^{k} E \log R_{t+1, k-(j-1)}=r
$$

where the second inequality follows from (A.2). Thus, we have that

$$
E\left\{h_{t}(\infty)-y_{t}(\infty)\right\}=\lim _{k \rightarrow \infty} E \log R_{t+1, k}-\lim _{k \rightarrow \infty}(1 / k) \sum_{j=1}^{k} E \log R_{t+j, k-(j-1)}=r-r=0
$$

Proposition 7. Define $h_{t}(k)$ and $y_{t}(k)$ as

$$
\begin{aligned}
h_{t}(k) & \equiv E_{t}\left\{\log E_{t+1}\left[\frac{X_{t+k}}{X_{t+1}}\right]-\log E_{t} \frac{X_{t+k}}{X_{t}}\right\}+\log E_{t} \frac{X_{t+1}}{X_{t}} \\
y_{t}(k) & \equiv-\left(\frac{1}{k}\right) \log E_{t}\left[\frac{X_{t+k}}{X_{t}}\right]+\log E_{t}\left[\frac{X_{t+1}}{X_{t}}\right] .
\end{aligned}
$$


Our proof goes through 3 steps. Step 1. Using the definitions of $J$ and $J_{t}$ and assumptions (i), (ii), (iii) and (a) we obtain

$$
J\left(\frac{X_{t+1}^{P}}{X_{t}^{P}}\right)=E\left[\log E_{t}\left[\frac{X_{t+1}}{X_{t}}\right]-E_{t}\left[\log \frac{X_{t+1}}{X_{t}}\right]\right]-\lim _{k \rightarrow \infty} E\left[h_{t}(k)\right] .
$$

Step 2. Using assumption (b) and taking limits we obtain

$$
\begin{aligned}
\lim _{k \rightarrow \infty}\left(\frac{1}{k}\right) J\left(\frac{M_{t+k}}{M_{t}}\right)= & E\left[\log E_{t}\left[\frac{X_{t+1}}{X_{t}}\right]-E_{t}\left[\log \left(\frac{X_{t+1}}{X_{t}}\right)\right]\right]-\lim _{k \rightarrow \infty} E\left[y_{t}(k)\right] \\
& +\lim _{k \rightarrow \infty}\left(\frac{1}{k}\right) J\left(E_{t}\left[\frac{X_{t+k}}{X_{t}}\right]\right) .
\end{aligned}
$$

Step 3. Using assumptions (c) and (d) we obtain $\lim _{k \rightarrow \infty} E\left[h_{t}(k)\right]=\lim _{k \rightarrow \infty} E\left[y_{t}(k)\right]$. Thus, using (d), we conclude the proof. More details are provided in the working paper version Alvarez and Jemann (2001).

Proposition 8. Define $x_{t+1, k}=\frac{E_{t+1} M_{t+k}}{E_{t} M_{t+k}}$. Given that $\Lambda_{t}$ is Markov, under the stated assumptions, we can write

$$
\lim _{k \rightarrow \infty} E_{t} \log x_{t+1, k}=\lim _{k \rightarrow \infty} \int\left[\log x_{k}\left(s^{\prime}, s\right)\right] Q\left(s, d s^{\prime}\right)
$$

where

$$
x_{t+1, k}=x_{k}\left(s^{\prime}, s\right)=\frac{\left(T^{k-1} f\right)\left(s^{\prime}\right)}{\int\left(T^{k-1}\right) f(\hat{s}) Q(s, d \hat{s})} .
$$

By Jensen's inequality $\int\left[\log x_{k}\left(s^{\prime}, s\right)\right] Q\left(s, d s^{\prime}\right) \leq 0$ since

$$
\int x_{k}\left(s^{\prime}, s\right) Q\left(d s^{\prime}, s\right)=\frac{\int\left(T^{k-1} f\right)\left(s^{\prime}\right) Q\left(s, d s^{\prime}\right)}{\int\left(T^{k-1}\right) f(\hat{s}) Q(s, d \hat{s})}=1 .
$$

By our assumption, $x_{k}\left(s, s^{\prime}\right) \geq l>0$; hence, for all $k, s, s^{\prime}$,

$$
-\infty<\log l \leq \log \left(\min \left\{x_{k}\left(s^{\prime}, s\right), 1+\varepsilon\right\}\right) \leq \log (1+\varepsilon)<\infty
$$

for any arbitrary $\varepsilon>0$. Because $\log \left(\min \left\{x_{k}\left(s^{\prime}, s\right), 1+\varepsilon\right\}\right)$ is uniformly bounded, Lebesgue dominated convergence applies. Note that we impose an artificial upper bound, $\log (1+\varepsilon)$ to get dominated convergence. With this bound, the integral can only get smaller. Thus, if we find that the integral equals zero, its upper bound, the artificial bound could not have mattered. Thus,

$$
\begin{aligned}
& \int \lim _{k \rightarrow \infty} \log \left(\min \left\{x_{k}\left(s^{\prime}, s\right), 1+\varepsilon\right\}\right) Q\left(s, d s^{\prime}\right) \\
= & \lim _{k \rightarrow \infty} \int \log \left(\min \left\{x_{k}\left(s^{\prime}, s\right), 1+\varepsilon\right\}\right) Q\left(s, d s^{\prime}\right) \\
\leq & \lim _{k \rightarrow \infty} \int \log \left(x_{k}\left(s^{\prime}, s\right)\right) Q\left(s, d s^{\prime}\right) \leq 0 .
\end{aligned}
$$


Hence, it suffices to show that

$$
\int \lim _{k \rightarrow \infty} \log \left(\min \left\{x_{k}\left(s^{\prime}, s\right), 1+\varepsilon\right\}\right) Q\left(s, d s^{\prime}\right)=0 .
$$

Under (i) or (ii),

$$
\begin{aligned}
\lim _{k \rightarrow \infty} x_{k}\left(s^{\prime}, s\right) & =\frac{\lim _{k \rightarrow \infty}\left(T^{k-1} f\right)\left(s^{\prime}\right)}{\lim _{k \rightarrow \infty} \int\left(T^{k-1}\right) f(\hat{s}) Q(s, d \hat{s})}=\frac{\lim _{k \rightarrow \infty}\left(T^{k-1} f\right)\left(s^{\prime}\right)}{\lim _{k \rightarrow \infty}\left(T^{k} f\right)(s)} \\
& =1 .
\end{aligned}
$$

Thus, because $\log \left(\min \left\{x_{k}\left(s^{\prime}, s\right), 1+\varepsilon\right\}\right)$ is bounded from below,

$$
\begin{aligned}
& \lim _{k \rightarrow \infty} \log \left(\min \left\{x_{k}\left(s^{\prime}, s\right), 1+\varepsilon\right\}\right)=\log \lim _{k \rightarrow \infty}\left(\min \left\{x_{k}\left(s^{\prime}, s\right), 1+\varepsilon\right\}\right) \\
= & \log \left(\min \left\{\lim _{k \rightarrow \infty} x_{k}\left(s^{\prime}, s\right), 1+\varepsilon\right\}\right)=0 .
\end{aligned}
$$

Proposition 9. Properties (a) and (b) define setwise convergence, and with $f($.$) bounded,$ expected values converge.

Proposition 10. First, we show a lemma that consumption equity prices and consumption equity dividend-price ratios are iid. Then we use the lemma to show that the kernel has permanent innovations.

Lemma A.1. Assume that $c_{t}$ is iid with $\operatorname{cdf} F$ and that $\eta<1$, where

$$
\eta \equiv \max _{c \in[c, \bar{c}]} \beta \tau^{1-\rho}\left\{\int\left(\frac{c^{\prime}}{c}\right)^{1-\gamma} d F\left(c^{\prime}\right)\right\}^{1 / \theta} .
$$

Then the price of consumption equity, $V_{t}^{c} / C_{t}=f^{*}\left(c_{t}\right)$, where the function $f^{*}$ is the unique solution to

$$
T^{*} f^{*}=f^{*}, f^{*}(c)=\psi c^{\gamma-1}
$$

for some constant $\psi>0$ and the operator $T$ is defined as

$$
(T f)(c)=\beta \tau^{1-\rho}\left\{\int\left(\frac{c^{\prime}}{c}\right)^{1-\gamma}\left[f\left(c^{\prime}\right)+1\right]^{\theta} d F\left(c^{\prime}\right)\right\}^{1 / \theta}
$$

Moreover, $V_{t}^{c}=\tau^{t} v\left(c_{t}\right) \equiv f\left(c_{t}\right) \cdot C_{t}$.

Proof. Using the pricing kernel (4.2), we obtain that consumption equity must satisfy

$$
\left[V_{t}^{c}\right]^{\theta}=E_{t}\left[\left[\beta\left(\frac{\tau c_{t+1}}{c_{t}}\right)^{-\rho}\right]^{\theta}\left[V_{t+1}^{c}+\tau^{t+1} c_{t+1}\right]^{\theta}\right] .
$$


Guessing that $V_{t}^{c}=v_{t} \tau^{t}$, we obtain

$$
v_{t}=\left\{E_{t}\left[\left[\tau \beta\left(\frac{\tau c_{t+1}}{c_{t}}\right)^{-\rho}\right]^{\theta}\left[v_{t+1}+c_{t+1}\right]^{\theta}\right]\right\}^{1 / \theta},
$$

and dividing by $c_{t}$ on both sides, we can write

$$
[T f](c)=\beta \tau^{1-\rho}\left\{\int\left(\frac{c^{\prime}}{c}\right)^{(1-\gamma)}\left[f\left(c^{\prime}\right)+1\right]^{\theta} d F\left(c^{\prime}\right)\right\}^{1 / \theta}
$$

where $f$ is the price-dividend ratio of the consumption equity: $f(c)=v(c) / c$. The operator $T$ can be shown to be a contraction: hence, it has a unique fixed point. Moreover, $\psi$ is given by

$$
\Psi=\beta \tau^{1-\rho}\left\{\int c^{(1-\gamma)}\left[f^{*}\left(c^{\prime}\right)+1\right]^{\theta} d F\left(c^{\prime}\right)\right\}^{1 / \theta}
$$

where $f^{*}$ satisfies $T f^{*}=f^{*}$.

Using Lemma A.1, we can write the return on the consumption equity as

$$
R_{t+1}^{c}=\tau \frac{v\left(c_{t+1}\right)+c_{t+1}}{v\left(c_{t}\right)}
$$

Then using (4.2), (4.5), and through some algebra, we get

$$
\begin{aligned}
x_{t+1, k} & =\frac{E_{t+1} M_{t+k}}{E_{t} M_{t+k}}=\frac{E_{t+1}\left[\beta^{\theta(t+1)} C_{t+1}^{-\rho \theta} Y_{t+1}^{\theta-1}\right]}{E_{t}\left[\beta^{\theta(t+1)} C_{t+1}^{-\rho \theta} Y_{t+1}^{\theta-1}\right]} \\
& =\left(1+\frac{1}{\psi} c_{t+1}^{\gamma-1}\right)^{\theta-1} / E_{t}\left[\left(1+\frac{1}{\psi} c_{t+1}^{\gamma-1}\right)^{\theta-1}\right] .
\end{aligned}
$$




\section{Appendix B: Data}

For Table 1, the data on monthly yields of zero-coupon bonds from 1946:12 to 1985:12 comes from McCulloch and Kwon (1993), who use a cubic spline to approximate the discount function of zero-coupon bonds using the price of coupon bonds. They make some adjustments based on tax effects and for the callable feature of some of the long-term bonds. The data for 1986:1 to 1999:12 are from Bliss (1997). From the four methods available, we use the method proposed by McCulloch and Kwon (1993). The second part of the sample does not use callable bonds and does not adjust for tax effects. Forward rates and holding periods returns are calculated from the yields of zero-coupon bonds. The one-month short rate is the yield on a one-month zero coupon bond. Yields are available for bonds of maturities going from 1 to 30 years, although for longer maturities, yields are not available for all years.

For Table 3, for the United States, equity returns are from Shiller (1998); short-term rates are from Shiller (1998) before 1926, and from Ibbotson Associates (2000) after 1926; and long-term rates are from Campbell (1996) before 1926, from Ibbotson Associates (2000) after 1926.

Ibbotson Associates' (2000) short-term rate is based on the total monthly holding return for the shortest bill not having less than one month maturity. Shiller (1998), for equity returns, used the Standard and Poor Composite Stock Price Index. The short-term rate is the total return to investing for six months at 4-6 month prime commercial paper rates. To adjust for a default premium, we subtract $0.92 \%$ from this rate. This is the average difference between T-Bills from Ibbotson Associates (2000) and Shiller's (1998) commercial paper rates for 1926-98.

The data for the United Kingdom is from the Global Financial Data-base. Specifically, the bill index uses the three-month yield on commercial bills from 1800 through 1899 and the yield on treasury bills from 1900 on. The stock index uses Bank of England shares exclusively through 1917. The stock price index uses the Banker's Index from 1917 until 1932 and the Actuaries General/All-Share Index from 1932 on. To adjust for a default premium, we have subtracted $0.037 \%$ from the short rate for 1801-99. This is the average difference between the rates on commercial bills and treasury bills for 1900-98.

For Table 5, the inflation rates are computed using a price index from January to December of each year. Until 1926, the price index is the PPI; afterwards, the CPI index from Ibbotson Associates (2000).

For Table 6, the aggregate equity index is from Global Financial Data, further described above. Inflation is based on the CPI, given by Global Financial Data. The Bank of England 
publishes estimates of nominal and real term structures for forward rates and yields. We use the series corresponding to the Svensson method, because these are available for the whole sample period, 1982-2000. See, http://www.bankofengland.co.uk/ and Anderson and Sleath (1999) for details.

\section{Appendix C: Small Sample Bias}

We derive here an estimate of the size of the small sample bias in our estimates in Table 1. For notational convenience, define

$$
\frac{a}{b} \equiv \frac{E\left[\log \frac{R_{t+1}}{R_{t+1,1}}\right]-E\left[h_{t}(\infty)\right]}{E\left[\log \frac{R_{t+1}}{R_{t+1,1}}\right]+J\left(1 / R_{t+1,1}\right)} .
$$

In Table 1 , we estimate this ratio as the ratio of the estimates $\widehat{a} / \widehat{b} \equiv f(\widehat{a}, \widehat{b})$. Using a second-order Taylor series approximation around the population values and considering that $\widehat{a}$ is an unbiased estimator of $a$, we can write

$$
\begin{aligned}
E\left[\begin{array}{l}
\hat{a} \\
\widehat{b}
\end{array}\right] & \simeq \frac{a}{b}+\left[\left(\frac{1}{b^{2}}\right)\left(\frac{a}{b} \operatorname{var}(\widehat{b})-\operatorname{cov}(\widehat{a}, \widehat{b})\right)\right]+\left[-\frac{a}{b^{2}} E(\widehat{b}-b)\right] \\
& \simeq \frac{a}{b}+\text { bias }_{1}+\text { bias }_{2} .
\end{aligned}
$$

We estimate bias $_{1}$ directly from the point estimates and the variance-covariance matrix of the underlying sample means. We estimate bias 2 by $\frac{1}{2} \frac{\hat{a}}{\hat{b}^{2}} \frac{1}{\hat{c}^{2}} \operatorname{Var}(\hat{c})$, with $\hat{c}$ the sample mean of $1 / R_{t, t+1}$. For forward rates, we estimate the size of the overall bias, bias $_{1}+$ bias $_{2}$, as $[-0.004,0.0073,-0.0012]$ for the three maturities in panel A of Table 1, where a negative number means that our estimate should be increased by that amount. Corresponding values for Panel B,C, and D are $[0.006,0.0132,0.0484],[-0.0072,-0.0079,-0.0115]$, and $[-0.0132,-0.0163,-0.0207]$. 
Table 1

Size of Permanent Component Based on Aggregate Equity and Zero-Coupon Bonds

\begin{tabular}{|c|c|c|c|c|c|c|}
\hline \multirow{5}{*}{ Maturity } & (1) & (2) & (3) & (4) & (5) & $(6)$ \\
\hline & Equity & Term & $\mathrm{J}(1 / \mathrm{R} 1)$ & Size of & (1) (2) & $P[(5)<0]$ \\
\hline & Premium & Premium & Adjustment & Permanent & & \\
\hline & & & for volatility & Component & $E\left[\log \left(R / R_{1}\right)\right]$ & \\
\hline & $E\left[\log \left(R / R_{1}\right)\right]$ & $E\left[\log \left(R_{k} / R_{1}\right)\right]$ & of short rate & $J(P) / J$ & $-E\left[\log \left(R_{k} / R_{1}\right)\right]$ & \\
\hline
\end{tabular}

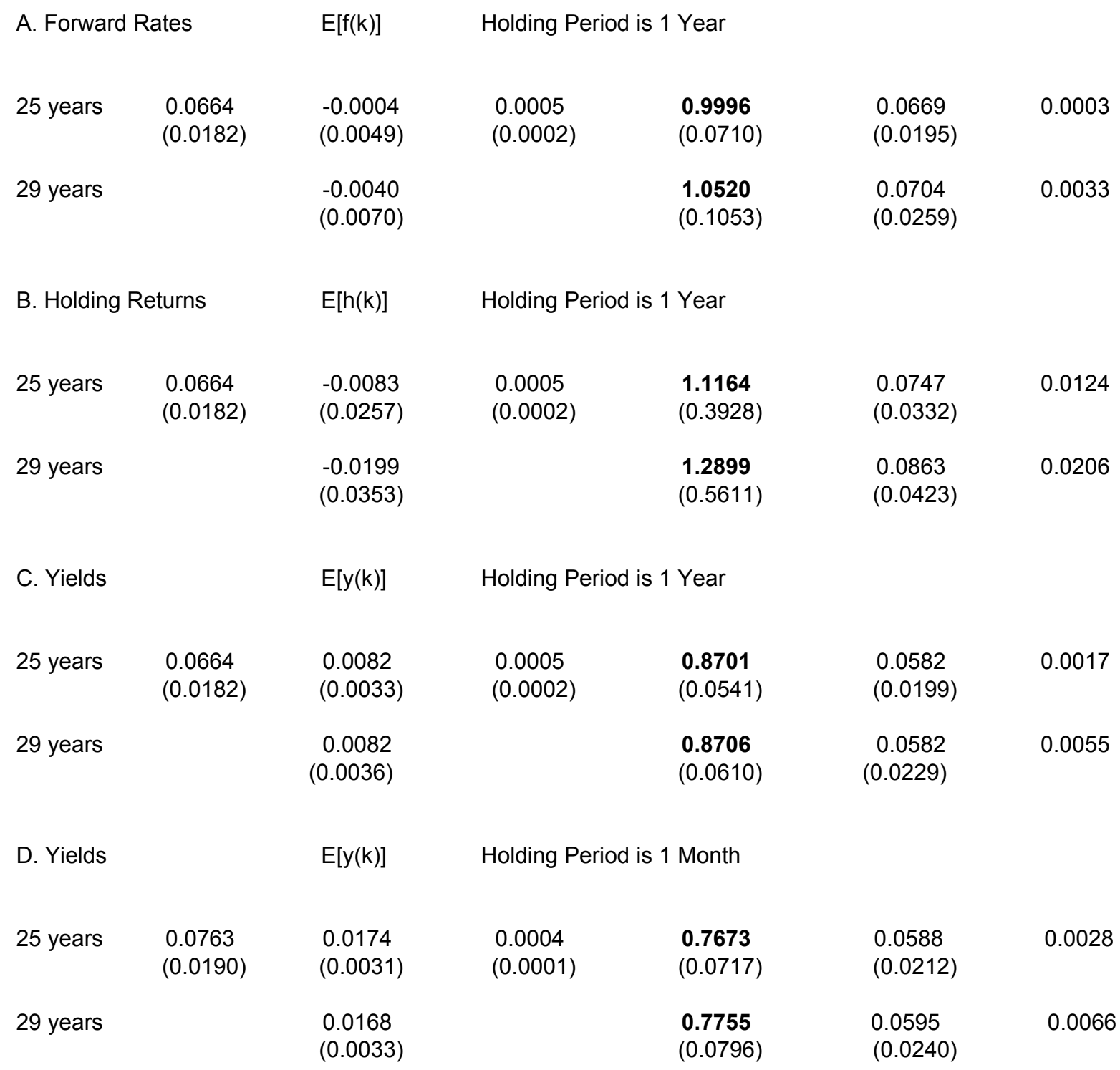

For A., term premia (2) are given by one-year forward rates for each maturity minus one-year yields for each month. For B., term premia (2) are given by overlapping holding returns minus one-year yields for each month. For C., term premia (2) are given by yields for each maturity minus one-year yields for each month. For A., B., and C., equity excess returns are overlapping total returns on NYSE, Amex, and Nasdaq minus one year yields for each month. For D., short rates are monthly rates. Newey-West asymptotic standard errors using 36 lags are shown in parentheses. $P$ values in (6) are based on asymptotic distributions. The data are monthly from 1946:12 to 1999:12. See Appendix B for more details. 
Table 2

Size of Permanent Component Based on Growth-Optimal Portfolios and 25-Year Zero-Coupon Bonds

\begin{tabular}{|c|c|c|c|c|c|}
\hline (1) & $(2)$ & (3) & $(4)$ & $(5)$ & (6) \\
\hline Growth & Term & $J(1 / R 1)$ & Size of & (1)-(2) & $\mathrm{P}[(5)<0]$ \\
\hline Optimal & Premium & Adjustment & Permanent & & \\
\hline & & for volatility & Component & $E\left[\log \left(R / R_{1}\right)\right]$ & \\
\hline$E\left[\log \left(R / R_{1}\right)\right]$ & $E\left[\log \left(R_{k} / R_{1}\right)\right]$ & of short rate & $J(P) / J$ & $-E\left[\log \left(R_{k} / R_{1}\right)\right]$ & \\
\hline
\end{tabular}

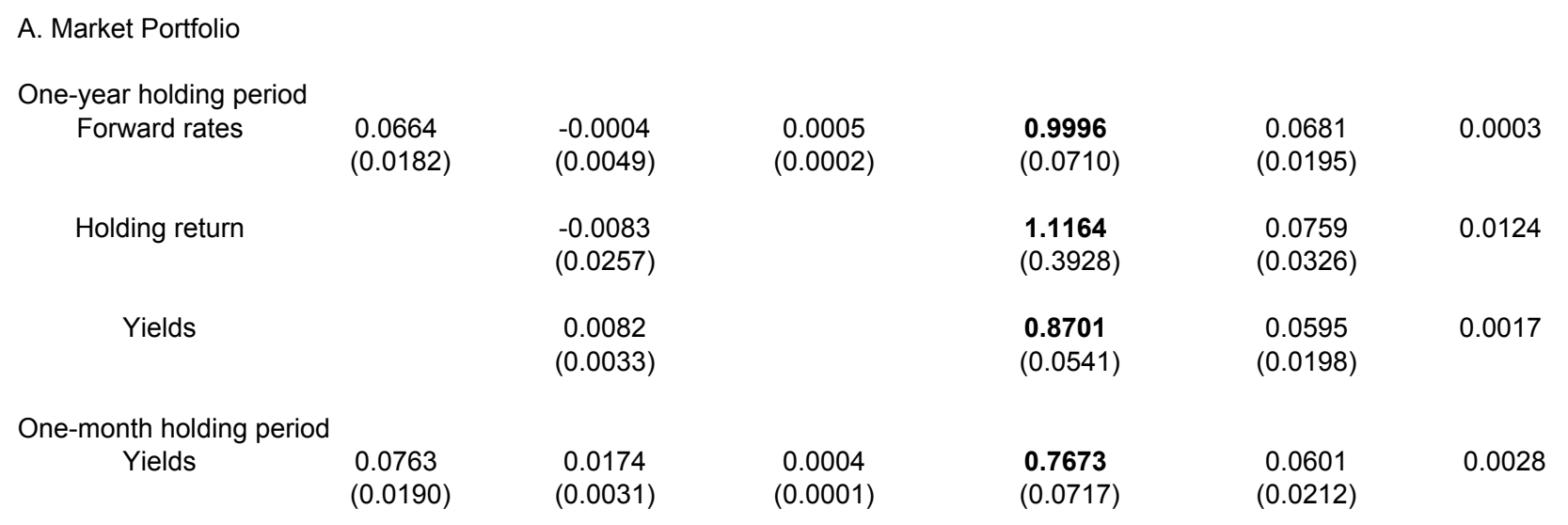

B. Growth-Optimal Leveraged Market Portfolio, (Portfolio weight: 3.47 for monthly holding period, 2.14 for yearly)

\begin{tabular}{|c|c|c|c|c|c|c|}
\hline \multicolumn{7}{|c|}{ One-year holding period } \\
\hline Forward rates & $\begin{array}{c}0.1095 \\
(0.0486)\end{array}$ & $\begin{array}{l}-0.0004 \\
(0.0049)\end{array}$ & $\begin{array}{c}0.0005 \\
(0.0002)\end{array}$ & $\begin{array}{c}\mathbf{0 . 9 9 9 8} \\
(0.0431)\end{array}$ & $\begin{array}{c}0.11 \\
(0.0473)\end{array}$ & 0.01 \\
\hline Holding return & & $\begin{array}{l}-0.0083 \\
(0.0257)\end{array}$ & & $\begin{array}{c}1.0708 \\
(0.2435)\end{array}$ & $\begin{array}{c}0.1178 \\
(0.0551)\end{array}$ & 0.0163 \\
\hline Yields & & $\begin{array}{c}0.0082 \\
(0.0033)\end{array}$ & & $\begin{array}{c}\mathbf{0 . 9 2 1 0} \\
(0.0386)\end{array}$ & $\begin{array}{c}0.1013 \\
(0.0477)\end{array}$ & 0.0169 \\
\hline \multicolumn{7}{|c|}{ One-month holding period } \\
\hline Yields & $\begin{array}{c}0.1689 \\
(0.0818)\end{array}$ & $\begin{array}{c}0.0174 \\
(0.0031)\end{array}$ & $\begin{array}{c}0.0004 \\
(0.0002)\end{array}$ & $\begin{array}{c}\mathbf{0 . 8 9 4 6} \\
(0.0518)\end{array}$ & $\begin{array}{c}0.1515 \\
(0.0814)\end{array}$ & 0.0315 \\
\hline \multicolumn{7}{|c|}{ C. Growth-Optimal Portfolio Based on the 10 CRSP Size-Decile Portfolios } \\
\hline \multicolumn{7}{|c|}{ One-year holding period } \\
\hline Forward rates & $\begin{array}{c}0.1692 \\
(0.0528)\end{array}$ & $\begin{array}{l}-0.0004 \\
(0.0049)\end{array}$ & $\begin{array}{c}0.0005 \\
(0.0002)\end{array}$ & $\begin{array}{l}\mathbf{0 . 9 9 9 9} \\
(0.028)\end{array}$ & $\begin{array}{c}0.1697 \\
(0.0525)\end{array}$ & 0.0006 \\
\hline Holding return & & $\begin{array}{l}-0.0083 \\
(0.0257)\end{array}$ & & $\begin{array}{c}1.0459 \\
(0.1551)\end{array}$ & $\begin{array}{c}0.1775 \\
(0.0621)\end{array}$ & 0.0021 \\
\hline Yields & & $\begin{array}{c}0.0082 \\
(0.0033)\end{array}$ & & $\begin{array}{c}\mathbf{0 . 9 4 8 8} \\
(0.0202)\end{array}$ & $\begin{array}{c}0.161 \\
(0.0518)\end{array}$ & 0.0009 \\
\hline \multicolumn{7}{|c|}{ One-month holding period } \\
\hline Yields & $\begin{array}{c}0.2251 \\
(0.0876)\end{array}$ & $\begin{array}{c}0.0174 \\
(0.0031)\end{array}$ & $\begin{array}{c}0.0004 \\
(0.0002)\end{array}$ & $\begin{array}{c}\mathbf{0 . 9 2 0 9} \\
(0.0318)\end{array}$ & $\begin{array}{c}0.2076 \\
(0.0872)\end{array}$ & 0.0086 \\
\hline
\end{tabular}


Table 3

Size of Permanent Component Based on Aggregate Equity and Coupon Bonds

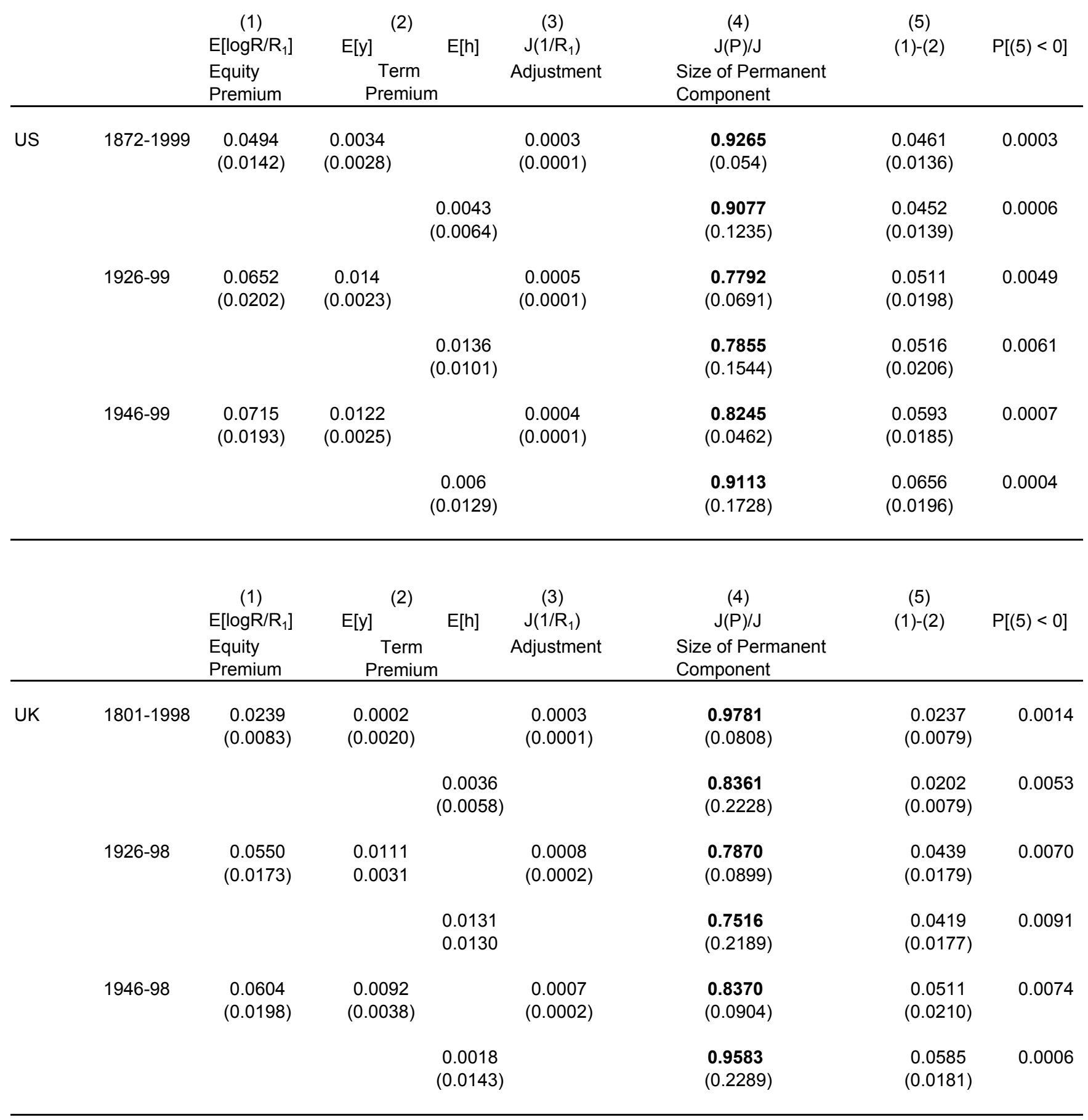

(1) Average annual log return on equity minus average short rate for the year.

(2) Average yield on long-term government coupon bond minus average short rate for the year.

(3) Average annual holding period return on long-term government coupon bond minus average short rate for the year.

Newey-West asymptotic standard errors with 5 lags are shown in parentheses. See Appendix B for more details. 
Table 4

Required Persistence for Bonds with Finite Maturities

\begin{tabular}{lccccc}
\hline $\begin{array}{l}\text { Maturity } \\
\text { (years) }\end{array}$ & & \multicolumn{4}{c}{ Term spread } \\
& 10 & & $0.50 \%$ & $1 \%$ & $1.50 \%$ \\
& 1.0000 & 0.9986 & 0.9972 & 0.9957 \\
& 20 & 1.0000 & 0.9993 & 0.9987 & 0.9980 \\
30 & 1.0000 & 0.9996 & 0.9991 & 0.9987 \\
\hline
\end{tabular}

Table 5

The Size of the Permanent Component due to Inflation

\begin{tabular}{|c|c|c|c|c|c|c|}
\hline $1947-99$ & & $\mathrm{AR}(1)$ & $\operatorname{AR}(2)$ & $\sigma^{2}$ & Size of per & nent component \\
\hline$\overline{\mathrm{AR} 1}$ & & 0.66 & & 0.0005 & 0.0021 & $(0.0009)$ \\
\hline AR2 & & 0.87 & -0.24 & 0.0004 & 0.0015 & $(0.0006)$ \\
\hline$(1 / 2 k) \operatorname{var}\left(\log P_{t+k} / P_{t}\right)$ & $\mathrm{k}=20$ & & & & 0.0043 & $(0.0031)$ \\
\hline & $k=30$ & & & & 0.0030 & $(0.0027)$ \\
\hline$J\left(P_{t+k} / P_{t}\right) / \operatorname{var}\left(\log P_{t+k} / P_{t}\right)$ & & $(k=20)$ & 0.46 & & & \\
\hline & & $(\mathrm{k}=30)$ & 0.45 & & & \\
\hline $1870-1999$ & & $\operatorname{AR}(1)$ & $\operatorname{AR}(2)$ & $\sigma^{2}$ & Size of per & nent component \\
\hline$\overline{\mathrm{AR} 1}$ & & 0.28 & & 0.0052 & 0.0049 & $(0.0013)$ \\
\hline AR2 & & 0.27 & 0.00 & 0.0052 & 0.0050 & $(0.0006)$ \\
\hline$(1 / 2 k) \operatorname{var}\left(\log P_{t+k} / P_{t}\right)$ & $k=20$ & & & & 0.0077 & $(0.0035)$ \\
\hline & $\mathrm{k}=30$ & & & & 0.0067 & $(0.0038)$ \\
\hline$J\left(P_{t+k} / P_{t}\right) / \operatorname{var}\left(\log P_{t+k} / P_{t}\right)$ & & $(k=20)$ & 0.47 & & & \\
\hline & & $(k=30)$ & 0.48 & & & \\
\hline
\end{tabular}

For the $\mathrm{AR}(1)$ and $\mathrm{AR}(2)$ cases, the size of the permanent component is computed as one-half of the spectral density at frequency zero. The numbers in parentheses are standard errors obtained through Monte Carlo simulations. For $(1 / 2 k) \operatorname{var}\left(\log P_{t+k} / P_{t}\right)$, we have used the methods proposed by Cochrane (1988) for small sample corrections and standard errors. See our discussion in the text for more details. 
Table 6

Inflation-Indexed Bonds and the Size of the Permanent Component of Pricing Kernels, U.K. 1982-99

Nominal Kernel

(1)

\begin{tabular}{|c|c|c|c|c|}
\hline \multirow{3}{*}{$\begin{array}{l}\text { Maturity } \\
\text { years }\end{array}$} & (1) & \multicolumn{2}{|c|}{ (2) } & \multirow{3}{*}{$\begin{array}{c}(3) \\
(1)-(2) \\
\text { Size of } \\
\text { Permanent } \\
\text { Component } \\
\text { J(P) }\end{array}$} \\
\hline & Equity & Forward & Yield & \\
\hline & $E[\log (R)]$ & $E[\log (F)]$ & $E[\log (Y)]$ & \\
\hline \multirow[t]{2}{*}{20} & $\begin{array}{c}0.1706 \\
(0.0197)\end{array}$ & $\begin{array}{c}0.0781 \\
(0.0038)\end{array}$ & & $\begin{array}{c}\mathbf{0 . 0 9 2 4} \\
(0.0206)\end{array}$ \\
\hline & & & $\begin{array}{c}0.0836 \\
(0.0053)\end{array}$ & $\begin{array}{c}\mathbf{0 . 0 8 7 0} \\
(0.0193)\end{array}$ \\
\hline \multirow[t]{2}{*}{25} & & $\begin{array}{c}0.0762 \\
(0.0040)\end{array}$ & & $\begin{array}{c}\mathbf{0 . 0 9 4 4} \\
(0.0212)\end{array}$ \\
\hline & & & $\begin{array}{c}0.0815 \\
(0.0046)\end{array}$ & $\begin{array}{c}\mathbf{0 . 0 8 9} \\
(0.0200)\end{array}$ \\
\hline
\end{tabular}

Real Kernel

(4)

(5)

(6)

(1)-(4)-(5)

Size of

Inflation Forward Yield Permanent

Rate Component

$E[\log (\pi)] \quad E[\log (F)] E[\log (Y)] \quad J(P)$

$\begin{array}{cccc}0.0422 & 0.0343 & & \mathbf{0 . 0 9 4 1} \\ (0.0063) & (0.0022) & & (0.0229) \\ & & & \\ & & 0.0348 & \mathbf{0 . 0 9 3 6} \\ & & (0.0017) & (0.0223)\end{array}$

$\begin{array}{ccc}0.0342 & & \mathbf{0 . 0 9 4 3} \\ (0.0023) & & (0.0230) \\ & & \\ & 0.0347 & \mathbf{0 . 0 9 3 7} \\ & (0.0018) & (0.0224)\end{array}$

Real and nominal forward rates and yields are from the Bank of England. Stock returns and inflation rates are from Global Financial Data. Asymptotic standard errors, given in parenthesis, are computed with the Newey-West method with 3 years of lags and leads. 

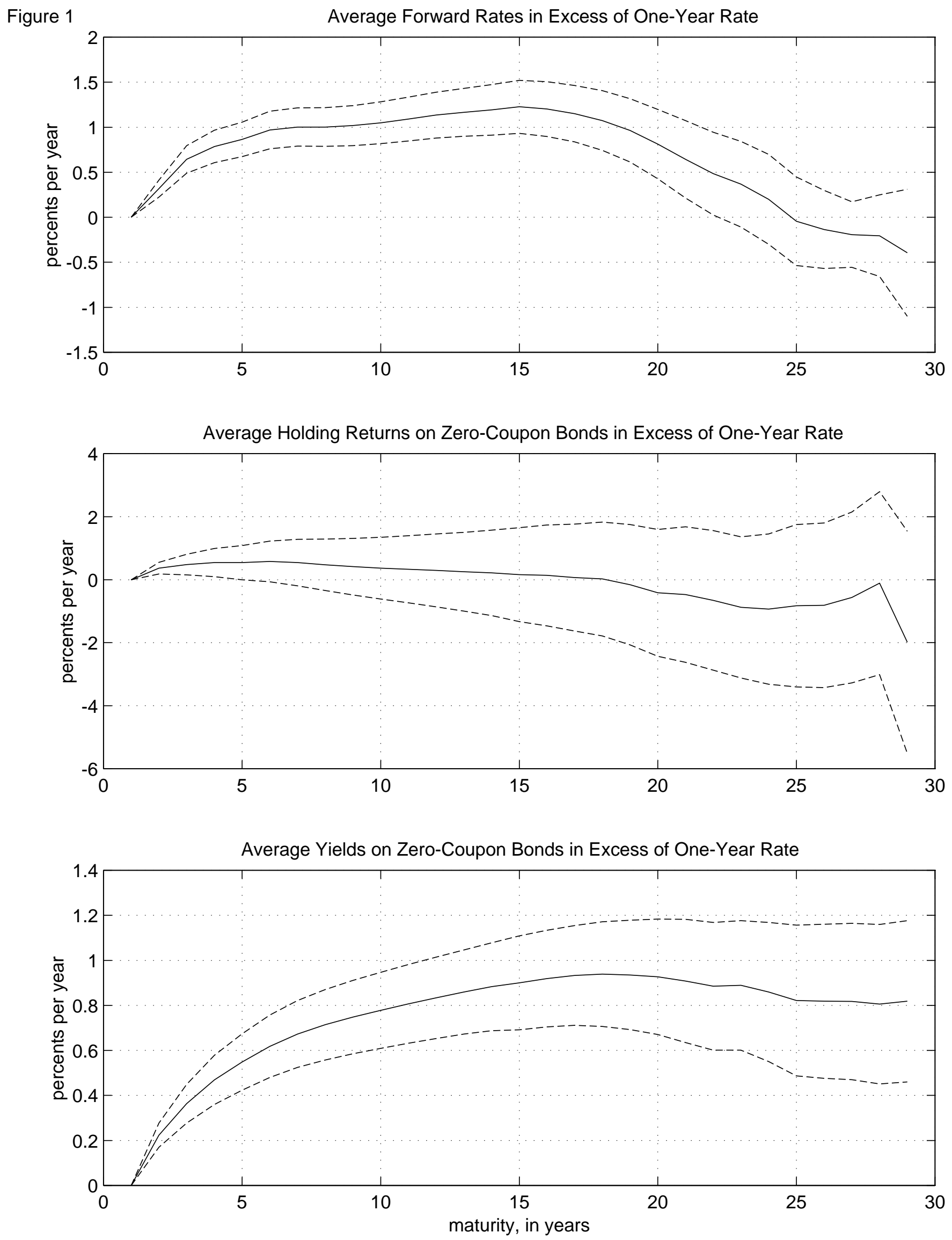

U.S., 1946:12 - 1999:12. Bands showing 1 asymptotic standard error. 
Figure 2

$1 / k$ times the variance of $k$-differences of Consumption divided by variance of first difference 1889-1997

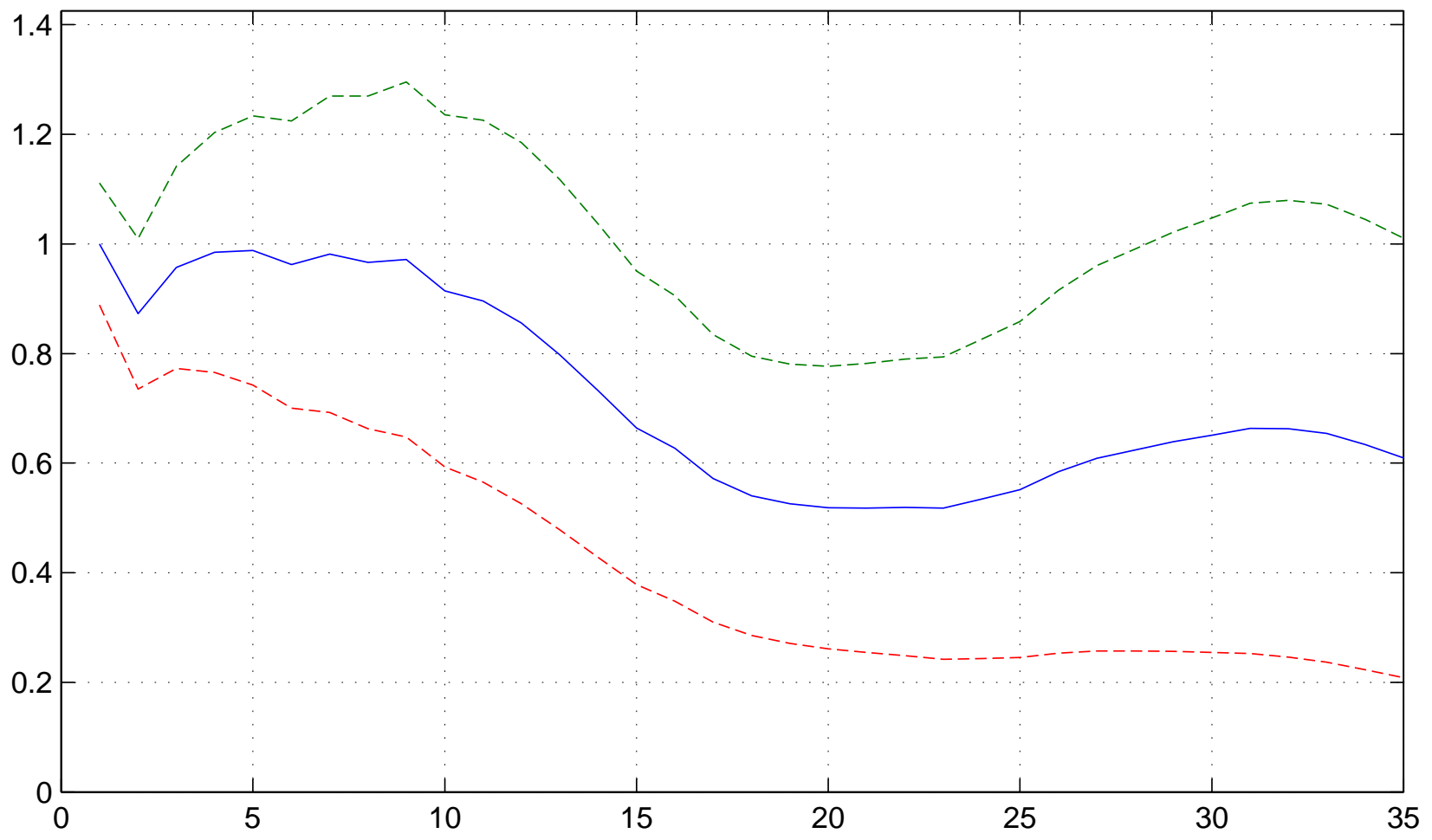

Figure 3

$1 / k$ times the variance of $k$-differences of Consumption divided by variance of first difference 1946-1997

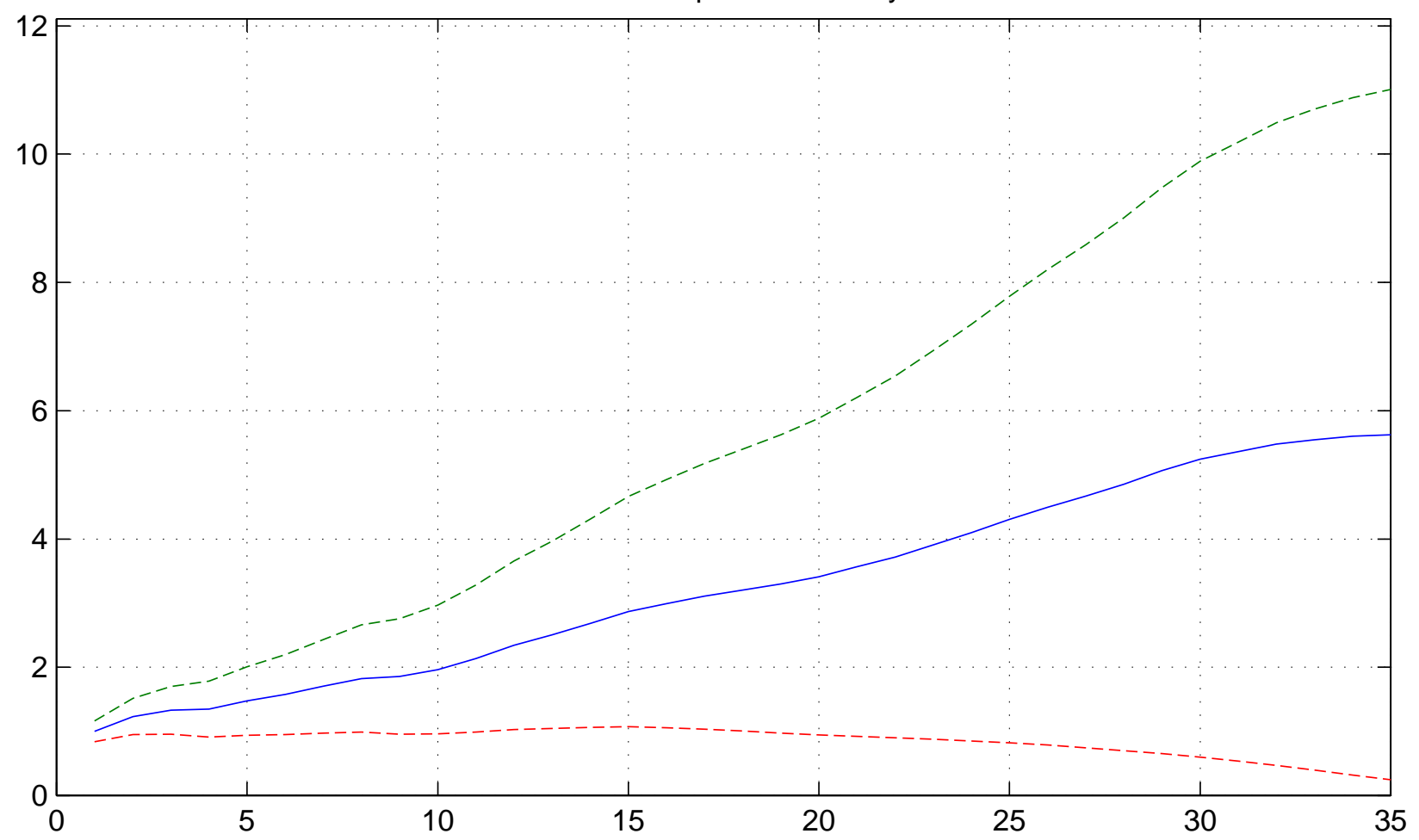

Bands showing 1 asymptotic standard error 